\title{
A light life together: photosensing in the plant microbiota
}

\author{
Aba Losi ${ }^{1}\left[\right.$. Wolfgang Gärtner ${ }^{2}(\mathbb{C}$
}

Received: 26 October 2020 / Accepted: 17 February 2021 / Published online: 1 March 2021

(c) The Author(s) 2021

\begin{abstract}
Bacteria and fungi of the plant microbiota can be phytopathogens, parasites or symbionts that establish mutually advantageous relationships with plants. They are often rich in photoreceptors for UVA-Visible light, and in many cases, they exhibit light regulation of growth patterns, infectivity or virulence, reproductive traits, and production of pigments and of metabolites. In addition to the light-driven effects, often demonstrated via the generation of photoreceptor gene knock-outs, microbial photoreceptors can exert effects also in the dark. Interestingly, some fungi switch their attitude towards plants in dependence of illumination or dark conditions in as much as they may be symbiotic or pathogenic. This review summarizes the current knowledge about the roles of light and photoreceptors in plant-associated bacteria and fungi aiming at the identification of common traits and general working ideas. Still, reports on light-driven infection of plants are often restricted to the description of macroscopically observable phenomena, whereas detailed information on the molecular level, e.g., protein-protein interaction during signal transduction or induction mechanisms of infectivity/virulence initiation remains sparse. As it becomes apparent from still only few molecular studies, photoreceptors, often from the red- and the blue light sensitive groups interact and mutually modulate their individual effects. The topic is of great relevance, even in economic terms, referring to plant-pathogen or plant-symbionts interactions, considering the increasing usage of artificial illumination in greenhouses, the possible light-regulation of the synthesis of plant-growth stimulating substances or herbicides by certain symbionts, and the biocontrol of pests by selected fungi and bacteria in a sustainable agriculture.
\end{abstract}

Keywords Biological photoreceptors $\cdot$ Phytochrome $\cdot$ LOV-domain $\cdot$ Plant-microbe interaction

\section{Introduction}

In the same environment in which plants receive their energy from light through photosynthetic activity, and from which they collect light inputs through photosensory proteins, also a large variety of microorganisms is thriving: they constitute the plant microbiota [1]. Some species of fungi and bacteria are well known and dangerous phytopathogens, but many are plant symbionts or commensals, and we see increasing evidence for their positive effects on plant growth and fitness, nutrient recycling and protection against pathogens [2, 3]. In other cases, microbes associated to plants influence

Aba Losi

aba.losi@unipr.it

1 Department of Mathematical, Physical and Computer Sciences, University of Parma, Parco Area delle Scienze 7/A, 43124 Parma, Italy

2 Institute for Analytical Chemistry, University of Leipzig, Linnéstrasse 3, 04103 Leipzig, Germany the production of secondary metabolites in medicinal or aromatic plants, or synthesize antibiotics, pesticides, and herbicides [4].

There is an increasing number of reports describing the impact that light has on plant-microbe association, not only via the photoreceptors of plants, but also through bacterial and fungal photosensory proteins that regulate the lifestyle of these microorganisms [5, 6]. Prominent examples include the phytopathogenic bacteria Pseudomonas syringae and Xanthomonas citri, whose photoreceptors influence growth patterns, motility, biofilm formation, and down-regulate virulence towards plants $[7,8]$.

Plants-associated bacteria and fungi share with their hosts red-/far red-light (RL/FRL) and blue light (BL)sensing domains/modules, chiefly phytochromes (Phy), and flavin-binding photoreceptors of the LOV (Light, Oxygen, Voltage) and cryptochrome/photolyase (Cry/PHR) superfamilies [9-11]. BLUF (Blue Light sensing Using Flavins) $[12,13]$ proteins and retinal-binding receptors ('microbial rhodopsins') [14] are definitely less represented, at least in 
the limited group of organisms taken into consideration in this work (vide infra) (Tables 1, 2).

In some cases, the number of candidate photoreceptors in members of the plant microbiota is relatively small: considering the phytopathogen Pseudomonas syringae pv. tomato DC3000, genes encoding two biliverdin IX $\alpha$ - (BV) binding bacteriophytochromes (PstBphP1 and PstBphP2) and a LOV protein (PstLOV) could be identified, all of them molecularly characterized [15-17]. In other plant-associated bacteria the number of photoreceptors is large, possibly due to their ability to live as facultative phototrophs: plant symbionts belonging to Methylobacteria have genes encoding on the average for two BphPs, six LOV- and three BLUF proteins [18]. These pink-pigmented facultative methylotrophic (PPFMs) bacteria normally thrive on leaves [19], where they consume methanol and other $\mathrm{C} 1$ compounds produced by plants, in turn promoting plant fitness by the production of phytohormones and iron-chelating compounds, by fixing nitrogen, by the uptake of metabolites, and by providing defense against infections [20]. Therefore, they are considered as biofertilisers and plants probiotics in the frame of sustainable agriculture [21]. Nevertheless, even though it was recently demonstrated that Methylobacteria photoreceptor candidates are functional [18], there are no reports on the effect of light in vivo, most importantly on possible roles of photoreceptors during the symbiosis with plants: we are, for example, not aware whether light affects the consumption of methanol or the production of phytohormones.

Also for fungi the role of photoreceptors during interaction with plants is scarcely known. Light regulates many aspects of fungal life and development, including circadian clock entrainment, hyphal growth, carotenoid and melanin synthesis, spore germination, development of structures for sexual and asexual reproduction, rate of growth, and directional development (phototropism) of reproductive structures [22]. Furthermore, fungal photoreceptors are involved in nutrient uptake, stress responses, pathogenicity, and secondary metabolism [23]. Given the rich photobiology of fungi, it is anticipated that photoreceptors may influence the pathogenicity against plants or the beneficial effects that some fungi have for agriculture such as the ability to control insect pests [24].

The plants-microbes-light interplay is definitely extremely complex, also because plants have their own photoreceptors that trigger a large variety of responses aiming to optimize photosynthesis, plant growth, fitness and the need to cope with other environmental factors (e.g., temperature, humidity). In plants, light regulates photomorphogenesis, levels of phytohormones, synthesis of secondary metabolites, or the release of volatile compounds triggering biosynthesis of plant defence molecules; all of these processes in turn affect the plant-microbe interaction [25]. Abiotic effects of light include changes in temperature and water status of plant parts, an important aspect also with respect to the evergrowing use of artificial lighting in greenhouses [6]. It is thus mandatory to disentangle light effects mediated by plant photoreceptors and those triggered by resident microorganisms during plant-microbe interaction. Examples for this complexity are the light effects on Peronosporaceae (oomycetes), wide spread phytopathogens causing downy mildew in diverse agricultural plants. In these oomycetes, RL can inhibit sporulation, e.g., in Peronospora belbahrii, such that exposure to this light quality during night-time effectively inhibits damages to basil plants [26]. However, RL is also
Table 1 Summary of photoreceptors types and number of genes encoding for the specified photoreceptors (as $\mathrm{X}$ ) in plant-associated bacteria for which a role of light has been described; see Table $\mathrm{S} 1$ for the specific strains

\begin{tabular}{|c|c|c|c|c|c|c|}
\hline Species & Feature & $\mathrm{BphP}^{\mathrm{a}}$ & $\mathrm{LOV}^{\mathrm{a}}$ & BLUF $^{\mathrm{a}}$ & $\mathrm{Cry} / \mathrm{PHR}^{\mathrm{a}}$ & $\mathrm{Rho}^{\mathrm{a}}$ \\
\hline Agrobacterium fabrum & Phytopathogen & $\mathrm{XX}$ & none & & $X$ & \\
\hline Azospirillum brasilense & Plant colonist & $\mathrm{XX}$ & none & & $\mathrm{X}$ & \\
\hline Bradyrhizobium sp. & Plant colonist & XXX & $\mathrm{X}$ & & $X X$ & \\
\hline Bradyrhizobium sp. & Plant colonist & XXX & $\mathrm{X}$ & & $\mathrm{X}$ & \\
\hline Bacillus amyloliquefaciens & Plant colonist & & $\mathrm{X}$ & & & \\
\hline Bacillus thuringiensis subsp. kurstaki & Entomopathogen & & & & $\mathrm{X}$ & \\
\hline Pseudomonas aeruginosa & Phytopathogen & $\mathrm{X}$ & & & $\mathrm{X}$ & \\
\hline Pseudomonas amygdali pv. tabaci & Phytopathogen & $\mathrm{XX}$ & $\mathrm{X}$ & & $\mathrm{X}$ & \\
\hline Pseudomonas cichorii & Phytopathogen & $\mathrm{X}$ & $\mathrm{X}$ & & $\mathrm{X}$ & \\
\hline Pseudomonas syringae pv. tomato & Phytopathogen & $\mathrm{XX}$ & $\mathrm{X}$ & & $\mathrm{X}$ & \\
\hline Pseudomonas syringae pv. syringae & Phytopathogen & $\mathrm{XX}$ & $\mathrm{X}$ & & $\mathrm{X}$ & \\
\hline Rhizobium leguminosarum pv. viciae & Plant colonist & $\mathrm{X}$ & $\mathrm{X}$ & & $\mathrm{X}$ & \\
\hline Xanthomonas campestris pv. campestris & Phytopathogen & $\mathrm{X}$ & $\mathrm{X}$ & & $\mathrm{X}$ & \\
\hline Xanthomonas citri subsp. citri & Phytopathogen & $\mathrm{X}$ & $\mathrm{X}$ & XX & $\mathrm{X}$ & \\
\hline Xanthomonas oryzae pv. oryzae & Phytopathogen & $\mathrm{X}$ & & & $X$ & \\
\hline
\end{tabular}

a: BphP bacteriophytochrome, $L O V$ Light, oxygen and voltage protein, $B L U F$ blue light sensing using flavins protein; $C r y / P H R$ cryptochrome/photolyase, Rho rhodopsin; see Table S1b-e for details 
Table 2 Summary of photoreceptors types and number of number of genes encoding for the specified photoreceptors as $\mathrm{X}$ in plant-associated fungi for which a role of light has been described; see Table S2 for the specific strains

\begin{tabular}{|c|c|c|c|c|c|c|}
\hline Species & Features & $\mathrm{BphP}$ & LOV & BLUF & Cry/PHR & Rho \\
\hline Alternaria alternata & Phytopathogen & $\mathrm{X}$ & $\mathrm{XX}$ & & $\mathrm{XXXX}$ & $\mathrm{XXX}$ \\
\hline Beauveria bassiana & Plant symbiont; Entomopathogen & $X$ & $\mathrm{XXX}$ & $X$ & $\mathrm{XXXX}$ & \\
\hline Botrytis cinerea & Phytopathogen & $\mathrm{XXX}$ & XXXX & & $\mathrm{XX}$ & $\mathrm{XX}$ \\
\hline Cercospora zeae-maydis & Phytopathogen & $X$ & XXXX & & $\mathrm{XXXX}$ & XXX \\
\hline Colletotrichum acutatum & Phytopathogen & $?^{\mathrm{a}}$ & $?^{\mathrm{a}}$ & $?^{\mathrm{a}}$ & $?^{\mathrm{a}}$ & $?^{\mathrm{a}}$ \\
\hline Cordyceps militaris & Entomopathogen & $\mathrm{X}$ & $\mathrm{XXX}$ & & $\mathrm{XXX}$ & \\
\hline Emericella nidulans & Saprophyte; model system & $\mathrm{X}$ & $\mathrm{XX}$ & & $X$ & $\mathrm{X}$ \\
\hline Fusarium asiaticum & Phytopathogen & & $\mathrm{XX}$ & & & \\
\hline Fusarium fujikuroi & Phytopathogen & $\mathrm{X}$ & XXXX & & XXX & $\mathrm{XX}$ \\
\hline Fusarium graminearum & Phytopathogen & & $\mathrm{XXX}$ & & & \\
\hline $\begin{array}{l}\text { Fusarium oxysporum } f . \mathrm{sp} . \\
\text { lycopersici }\end{array}$ & Phytopathogen & $\mathrm{X}$ & XXXX & & XXX & XXX \\
\hline Magnaporthe oryzae & Phytopathogen & $\mathrm{X}$ & $\mathrm{XXXXX}$ & & $\mathrm{XX}$ & \\
\hline Metarhizium acridum & Plant colonist; Entomopathogen & $\mathrm{X}$ & XXX & & XXX & \\
\hline Metarhizium robertsii & Plant colonist; Entomopathogen & $\mathrm{X}$ & $\mathrm{XXX}$ & & $\mathrm{XXX}$ & \\
\hline Neurospora crassa & Saprophyte; model system & $\mathrm{X}$ & $\mathrm{XXX}$ & & $\mathrm{XX}$ & $\mathrm{X}$ \\
\hline Sordaria fimicola & Plant colonist; Dung fungus; & & $X$ & & & \\
\hline Trichoderma atroviride & Plant colonist & $\mathrm{X}$ & $\mathrm{XX}$ & & $\mathrm{XXX}$ & \\
\hline Trichoderma harzianum & Plant colonist & $X$ & $\mathrm{XX}$ & & XXX & \\
\hline Trichoderma reesei & Plant colonist & $\mathrm{X}$ & $\mathrm{XX}$ & & $\mathrm{XXX}$ & \\
\hline Tuber borchii & Plant symbiont /parasite & $\mathrm{X}$ & $X$ & & $X$ & \\
\hline Tuber melanosporum & Plant symbiont /parasite & $\mathrm{X}$ & $\mathrm{X}$ & & & \\
\hline Ustilago maydis & Phytopathogen & $\mathrm{X}$ & $\mathrm{X}$ & $\mathrm{X}$ & $\mathrm{XXXX}$ & $\mathrm{XXX}$ \\
\hline Venturia inaequalis & Phytopathogen & XXX & XXX & & $X$ & $\mathrm{XX}$ \\
\hline Zymoseptoria tritici & Phytopathogen & $X$ & XXX & & XXX & $\mathrm{XX}$ \\
\hline
\end{tabular}

${ }^{a}$ No genome project available; see Table S2b-f for details

reported to increase the in-vitro germination capacity of Peronospora effusa that causes downy mildew in spinach [27]. In these microorganisms, though, photoreceptors are still to be identified and functionally characterized.

In this work we review, after a brief summary of the molecular properties of photoreceptors present in the plant microbiota, the current knowledge about the influence of visible light on the microorganisms traits that have or might have an effect on plant-microbe interaction, limiting our considerations to bacteria and fungi. Whenever possible, the photoreceptors related to given phenomena are indicated. In conclusion, we propose possible directions for the future developments of this topic.

\section{Photoreceptors in the plant microbiota}

Due to the many facets that plant-microbes interactions provide, we have chosen to consider and search photoreceptors candidates only in plant-associated bacteria and fungi for which light-regulated responses have been reported, be they correlated or not to individual photosensory proteins (Tables 1, 2, S1 and S2). For the widespread Methylobacteria, the reader is referred to a recent publication keeping in mind that so far no light-dependent response has been reported for this genus [18]. Photoreceptor candidates in the selected microbes belong to the following classes (Table 1): $\mathrm{BV}$-binding, RL/FRL Phy proteins $(\mathrm{BphP}=$ bacteriophytochromes; FphP = fungal phytochromes); BL-sensing LOV, Cry/PHR (PHR, PHotoRepair) and BLUF proteins; microbial rhodopsins (Rho), covering a wide spectral range. In the following, we provide a basic functional description for the various photoreceptor classes.

Phy-proteins are characterised by covalently bound open-chain tetrapyrrole chromophores (bilins) that undergo double bond photoisomerisation [28]. This photochemical reaction forming the 'photoproduct' causes a shift of the absorption maxima of the parental ('dark') state to longer wavelengths. Most plant- and bacteria-derived phytochromes show dark states with absorption maxima around 650-665 nm (RL-absorbing, Pr state referring here to canonical plant- and cyanobacterial-derived phys) 
and photoproducts with absorption maxima in the range of 710-730 nm (FRL-absorbing, Pfr). So-called bacteriophys that carry biliverdin XI $\alpha$ as chromophore undergo switches between $700(\mathrm{Pr})$ and $750 \mathrm{~nm}$ (Pfr). Exceptions from the rule are the 'bathy'-Phys, in which the parental state shows a long wavelength-absorption (Pfr) that is switched into a RL-absorbing Pr form. Exceptions to this Pr-to-Pfr conversion are cyanobacteriochromes that again photoisomerize and show photochromicity, but cover the entire UVA-visible/near infrared spectral range [29]. Phy proteins that show a three-domain module (PAS-GAFPHY, PAS $=$ Per Arnt Sim, GAF = cGMP-specific phosphodiesterases, cyanobacterial adenylate cyclases, and formate hydrogen lyase transcription activator FhlA, PHY = Phytochrome-specific domain [30]) are named 'canonical' Phys. This three-domain arrangement instrumental to maintain the spectral, photochromic and photochemical properties. Different to plant and canonical cyanobacterial phytochromes that carry the chromophore-binding cysteine within the GAF domain, BphPs and FphPs bind the BV chromophore through a cysteine residue located very close to the N-terminus in the PAS domain, however, also these phytochromes embed the bilin chromophore in the GAF domain [28]. Their Pr and Pfr forms absorb maximally at ca. 700 and $750 \mathrm{~nm}$, respectively, irrespective of the dark state being the Pr state or the Pfr state, as is the case in the 'bathy'-phytochromes [31]. Both BphP and FphP phytochromes undergo similar light triggered reactions, starting, for both Pr and Pfr forms, with the ultrafast photoisomerization of the bilin chromophore in the ps time range, followed by several, in some proteins relatively few intermediates that thermally interconvert into each other and finally result, within several hundred $\mathrm{ms}$, in the formation of the photoproduct [32]. The overall process, in some BphP, runs with a low quantum yield $(\Phi)$ of $2 \%$ (PsBphP1 of $P$. syringae [17]) and maximally with $\Phi=20 \%$ for a BphP of M.radiotolerans [18]). Bacterial and fungal phytochromes accomplish their regulating function through a signaling domain located in the C-terminal part of the protein (Figs. 1, 2). Most frequently found, in fact exclusively for the cases discussed in this paper, is the two-component signaling system, composed of histidine kinases (HKs) and their interacting, cognate response regulators (RRs) [33]. RRs can be present as independent proteins, their encoding genes often arranged in an operon with the Phy-encoding gene, but RRs are also found fused to the C-terminal end of HK-bearing Phy. The process of activation and functioning is fully conserved in these systems such that, upon activation of the HK by the sensor module, here the light-sensing part of the photoreceptor, a conserved histidine in the HK domain is phosphorylated employing the $\gamma$-phosphate of a non-covalently bound ATP. Only in this phosphorylated state, the RR forms a complex with the activated HK and

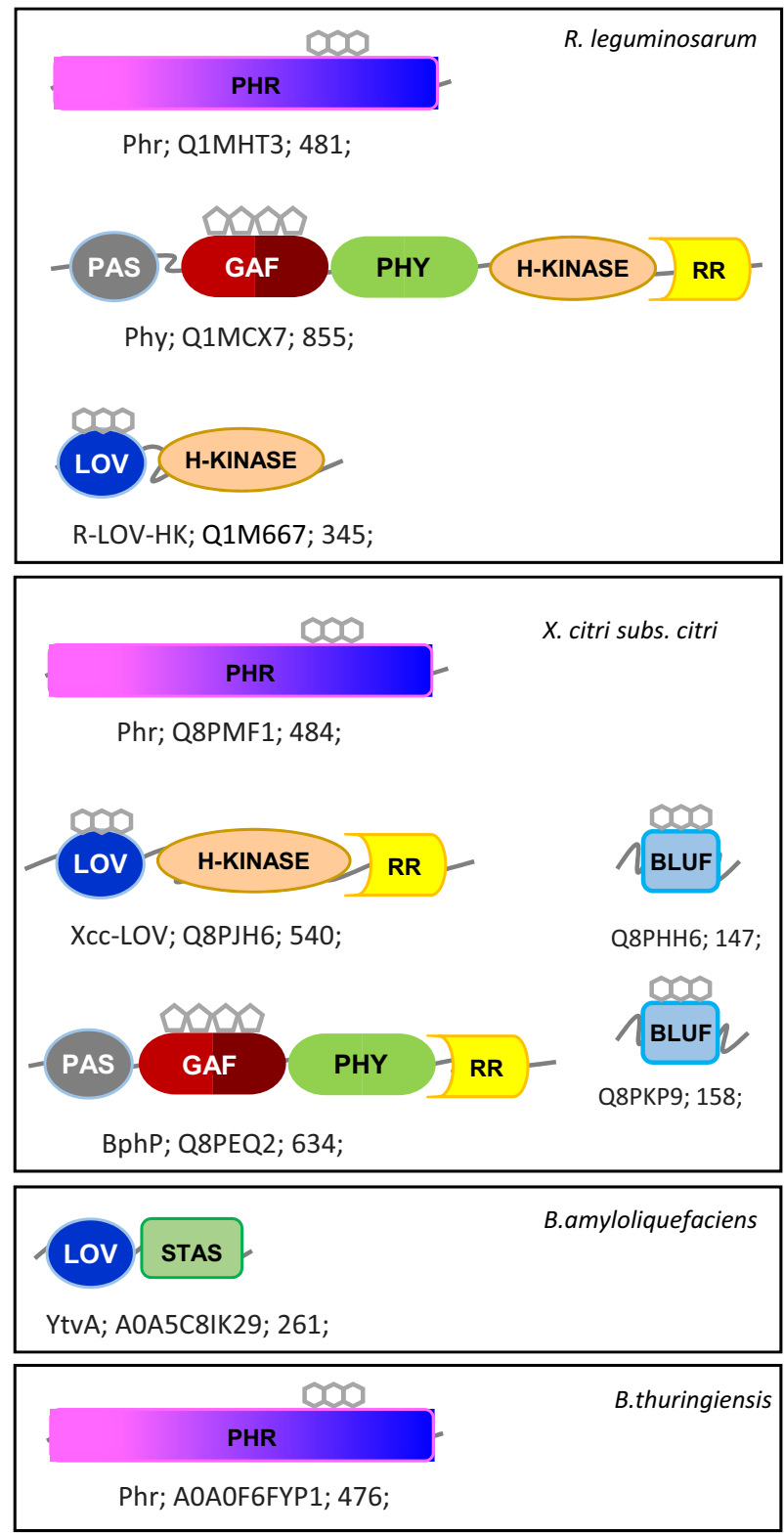

Fig. 1 Photoreceptor systems of selected bacteria interacting with plants; see Table S1 for details on the single organisms. The conventional names (if existing), protein codes (UniProt), and number of amino acids are given for each protein. Flavin chromophore (in LOV, Cry/PHR and BLUF domains) and BV in phytochromes are schematically represented

takes over the phosphate group that is then covalent bound to one conserved aspartate of the RR. After phosphate transfer, the complex falls apart and the now activated RR performs its function by, e.g., regulating flagellar activity for taxis or modifying the gene expression program [34]. In some cases, no effector domain is present, but a second PAS domain is found instead (Tables S1 and S2). We note that some BphPs bear instead effector domains that regulate the turnover of the second messenger molecule cyclic 
Fig. 2 Photoreceptor systems of selected fungi related to plants; see Table S2 for details on the individual organisms. Top, non pathogenic, bottom, plant pathogenic fungi. The conventional names (if existing), protein codes (UniProt), and number of amino acids are given for each protein. Flavin chromophore (in LOV, Cry/PHR and BLUF domains), BV in phytochromes and retinal in rhodopsins are schematically represented
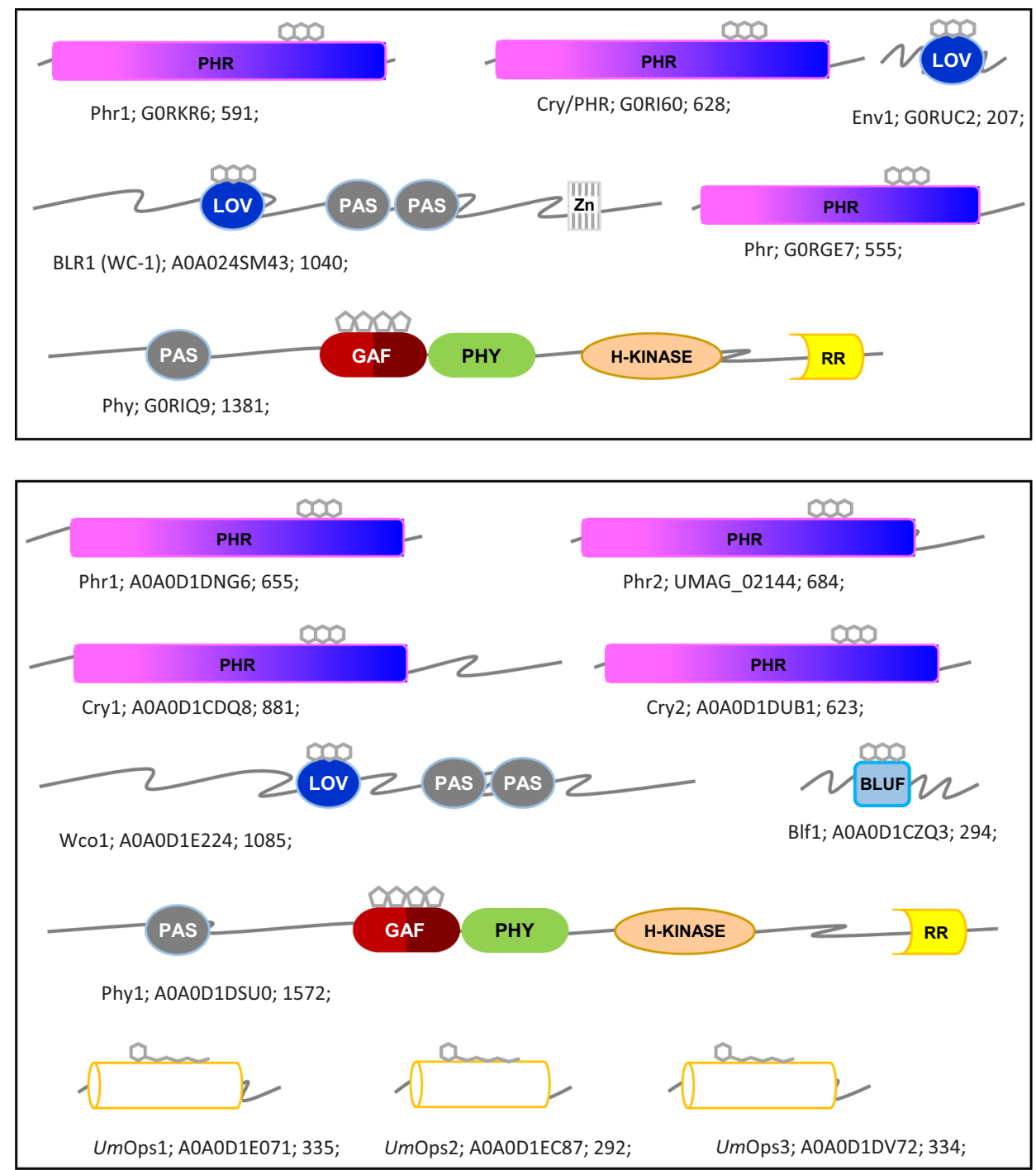

dimeric guanosine monophosphate (c-di-GMP) [35], but they are not present in the organisms listed here.

LOV domains incorporate FMN (flavin mononucleotide) or FAD (flavin adenine dinucleotide) as chromophores within a PAS-like $\alpha / \beta$ fold comprising ca. 110 aa [36]. They are widespread in the three domains of life, from plant to archaea, from bacteria to fungi, but are not present in animals [37]. In the dark-adapted state, the chromophore is embedded non-covalently in fully oxidized form absorbing maximally at ca. $450 \mathrm{~nm}\left(\mathrm{LOV}_{450}\right)$ and showing a bright green fluorescence. BL illumination induces formation of a covalent FMN-Cys adduct in the short $\mu$ s time scale which is strongly blue shifted $\left(\mathrm{LOV}_{390}\right)$ with loss of fluorescence. $\mathrm{LOV}_{390}$ recovers thermally, in the dark, to $\mathrm{LOV}_{450}$ within few seconds, minutes or even many hours [36].

LOV-based photoreceptors constitute a variegate superfamily, with diverse associated effector/regulatory domains [37]. In our list of plant-associated bacteria (Table S1) we note chiefly LOV-linked histidine kinases (HK) of the two-component system, RR, and STAS (Sulphate Transporter and AntiSigma factor antagonist) domains [38]. In fungi (Table S2), the typical members are VVD (Vivid), made up of a standalone LOV domain with flanking regions (referred to as short-LOV), and WC-1 (White collar-1) proteins that bear PAS domains and Zn-finger domains to interact with DNA in transcription factor complexes [23].

Members of the Cry/PHR (Cryptochrome/photolyases) superfamily comprise: i. PHR photoenzymes that exploit BL to repair ultraviolet-(UV) generated photoproducts in DNA; ii. Cry proteins, originally discovered in plants and insects and characterized as photosensors without PHR activity; iii. bifunctional Cry proteins that possess photorepair and photosensing activity, such as the Cry-DASH clade (Drosophila, Arabidopsis, Synechocystis, Human) [39, 40]. Common to all Cry/PHR photoreceptors is the PHR region (ca. 480 aa) that hosts the FAD chromophore and most often a second chromophore functioning as an antenna and transferring energy to FAD. Cry proteins may have a 
C-terminal extension involved in signalling [41]. To repair pyrimidine dimers produced in DNA by UV radiation, the FAD molecule of PHR must be in the fully reduced hydroquinonic form $\mathrm{FADH}^{-}$, the functionally crucial reaction is a photoinduced electron transfer to the di-pyrimidine dimer [42]. Cry photo-induced reactions are, to some extent, still a matter of debate. A major question is the redox state of the bound FAD in vivo. Few systems have been studied in detail and the picture emerging is continuously developing, with diverse mechanisms being proposed; the vast majority of action spectra for Cry-regulated photosensory responses indicate that the dark-adapted state contains fully oxidised FAD, in agreement with their main role as BL receptors, although exceptions do exist [43]. Intramolecular photoinduced electron transfer chains from aromatic amino acids to the fully oxidised or semi-reduced FAD are held as the basis of Cry photochemistry [44]. In this manuscript we will not predict the function of Cry/PHR proteins, trying to distinguish between their activity as photoenzymes or/and photosensors, unless it is clear from experimental reported data.

BLUF domains (ca. $100 \mathrm{aa}$ ) are $\alpha / \beta$ folds with a structural arrangement reminiscent of ferredoxin [12]. They bind non-covalently a fully oxidised FAD chromophore. Their photocycle involves two conserved residues (a tyrosine and a glutamine) that via ultrafast electron transfer reactions promote hydrogen bond rearrangement around the FAD chromophore. As a result, a transient species is formed absorbing bathochromically by few $\mathrm{nm}$ to the dark-adapted state, but without an evident change of the FAD redox state [12]. BLUF proteins are solely present in bacteria, euglenoids, and some fungi (vide infra), and are less variegate than LOV proteins as for effector/regulative domains linked to the photo-sensing unit [13]. Importantly, some BLUF proteins bear effector domains that regulate the level of cyclic nucleotides that act as second messengers (cAMP, cGMP, c-di-GMP) [38]. The majority of bacterial BLUF domains, however, do not show any linked effector domain fused to the same protein (referred to as "short-BLUF").

Microbial rhodopsins (Rho) are based on the same seven-helix membrane-intrinsic protein structure as present in visual animal rhodopsins, although their functions are highly divergent [45]. The retinal chromophore is bound via a protonated Schiff base to a lysine residue located in the seventh helix, but, different to animal Rho, these proteins incorporate the all-trans isomer that photo-isomerises (in most cases) into its 13-cis isomer. Photoisomerisation of the retinal occurs on the ps time-scale, followed by formation of several transient species and closure of the photocycle typically on the ms-to-s time range. Many microbial rhodopsins are able to actively transport ions (pumps, like bacteriorhodopsin, halorhodopsin, and proteorhodopsins) or act as light-gated ion channels (channelrhodopsins) or photosensors (e.g., sensory rhodopsins) [45]. Recent years have seen identification of enzyme-rhodopsins, where Rho proteins are fused to effector domains that in turn activate a signal transduction chain [46]. In the list of microorganisms considered here Rho photoreceptors were solely detected in fungi, not in bacteria.

\section{Light-regulation in the plant microbiota}

\subsection{Photoresponses and photoreceptors in plant-associated bacteria}

Perhaps one of the most prominent features of bacterial photosensing proteins is the finding that they perform lightindependent functions besides serving as photoreceptors $[5,7]$. To clarify this aspect, it is useful to consider information available for some well-known plant pathogens of the genera Xanthomonas and Pseudomonas. X. citri subsp. citri $(X c c)$ is the causal agent of citrus canker, causing significant agricultural losses worldwide [47]. This gammaproteobacterium possesses one $\mathrm{BphP}$, one $\mathrm{LOV}$ protein, two BLUF proteins, and a PHR (Table 1, Table S1). The LOV protein, $X c c \mathrm{LOV}$ has a typical $\mathrm{LOV}+\mathrm{HK}+\mathrm{RR}$ architecture (Fig. 1) and shows the canonical spectral features of LOV photochemistry [48]. The activity of the HK domain is enhanced upon BL illumination, but only down-regulated and not supressed in the dark. Studies with knock-out mutant strains devoid of XccLOV evidenced that this photoreceptor promotes bacterial adhesion to leaves, but opposite, protects hosts from necrosis in a light-dependent manner. Other effects are light-independent: XccLOV is instrumental for formation of flagella, it inhibits swarming motility and formation of the EPS (extracellular polymeric substance). Finally, some effects are detected in the dark, but influenced by $\mathrm{BL}$ in a complex manner, e.g., timing of biofilm formation, protection of $X c c$ against oxidative damages, limitation of damages to plant tissues and of host defence responses [7, 49]. Xcc is considered a hemibiotrophic pathogen, i.e., it relies on metabolites derived from plant cells to survive. In this view, the observation that a photoreceptor somehow protects the infected plant from massive damages might make sense. In Xanthomonas campestris pv. campestris, light negatively regulates $X c c$ virulence towards plants and FRL inhibits the virulence systems of this bacterium. Light also inhibits xanthan production and biofilm maturation, phenomena probably triggered by a low Pfr:Pr ratio of the bathy phytochrome $X c c \mathrm{BphP}$ [50]. The results obtained with these two Xanthomonads indicate that photoreceptors influence processes that in turn affect interaction with the plant host, although investigation is by far not complete. Another important hemibiotrophic foliar pathogen is Pseudomonas syringae pv tomato DC3000 (Pst), for which interaction with plants can be conveniently studied in the model system 
Arabidopsis thaliana [51]. Pst is the causal agent of bacterial speck in Lycopersicon esculentum, producing severe loss of crops worldwide [52]. As mentioned in the introduction, Pst is equipped with the two RL/FRL sensing, BV binding Pst $\mathrm{BphP} 1$ and PstBphP2 and the flavin binding, BL sensing PstLOV (Table S1). Deletion mutants showed that these photoreceptors limit and delay leaf colonization and damages to infected $A$. thaliana plants; furthermore, they downregulate swarming motility $[8,53,54]$. The locus encoding $P s t \mathrm{LOV}$ is part of a genomic island, active during infection, that was proposed to be acquired by the bacterium through horizontal gene transfer [55]. The dominant regulatory function of PstLOV on the expression of genes encoding principal and alternative sigma factors and their downstream targets could be documented using PstLOV-knock-out mutants that exhibited de-repressed, enhanced reactivity. Many of these genes (and their gene products) are linked to general bacterial growth, virulence, and quorum sensing [55]. Recent work evidenced BL up-regulation of secretion system genes and RL down-regulation of coronatine, a bacterial toxin that induces stomata opening. In addition, lighttreated $P s t$ cells showed a larger virulence at dawn than at dusk, possibly due to an increased level of stomata opening [56]. Study of the molecular properties of the two BphPs in Pst revealed clear differences in their regulatory role for the bacterium. Both proteins show a very similar modular arrangement of PAS-GAF-PHY-HK domains (PstBphP2 carries motifs for a second, yet somewhat corrupted HK [54]). However, while PstBphP1 is readily loaded with its BV chromophore by its genuine heme oxygenase (arranged in an operon), its ortholog, Pst $\mathrm{BphP} 2$, is hardly furnished with the BV chromophore under conditions of heterologous expression in Escherichia coli, even if the gene encoding Pst $\mathrm{BphP} 2$ is cloned precisely at the position of its $\mathrm{P} 1$ orthologue. This failure of chromophore incorporation, however, has to be considered an expression-prone artefact, as could be demonstrated by comparing the biological properties of $B s t \mathrm{BphP1}$ - or BstBphP2-knock-out mutants with those of the WT cells. $\Delta B s t \mathrm{BphP1}$ cells showed a stronger swarming activity, whereas $\Delta B s t \mathrm{BphP} 2$ cells were negatively affected in their growth capacity and, in addition, these cells showed a remarkably different dendritic swarming behaviour [54]. The double phytochrome-knock out mutant cells reproduced the effect found for the deletion of only $B s t \mathrm{BphP} 2$, and triple mutant cells $(\Delta B s t \mathrm{BphP} 1, \mathrm{BphP} 2$, and $\Delta \mathrm{LOV})$ levelled in between the enhanced growth of the LOV-mutant and the diminished growth of BstBphP2. These findings for Pst on reduced motility concur with similar studies in Agrobacterium fabrum (formerly $A$. tumefaciens) for which a dependence on the spectral quality of the incident light was found [57]. The different swarming behaviour of the individual Pst knock-out mutants was investigated in greater detail by Moyano et al. [8]. These authors could identify an increased flagellin concentration in the $\Delta \mathrm{BphP} 1$ and $\Delta \mathrm{BphP} 2$ mutants ( $\triangle \mathrm{LOV}$ mutants were not investigated in this assay). Interestingly, a larger concentration of flagellin was also found for these two mutants, when the bacteria were kept in the dark. These two knock-out mutants reduced the capability to adhere to tomato leaves. This finding concurs with more detailed in vitro investigations of the WT- and mutated bacteria aiming at the concentration and capability to develop biofilms. Again, the BphP-mutants nearly lost the capability to adhere to a glass surface, and this property could be only partially rescued when the mutated strain was complemented for the mutated gene. The wide variation of $P$ st functional properties in response to light, as evidenced by the various knock-out mutants, identify the photoreceptors as major regulatory elements for the expression of a large number of genes. Other effects of RL treatment include enhanced resistance of tomato plants to Pst [58] and the delay of the programmed death of $P s t$-infected tobacco leaves [59], although a link to specific photoreceptors was not established in these last two cases.

Further studies on the virulence of Pst towards Arabidopsis thaliana, again employing individual knock-out mutants clearly demonstrate a regulatory function of the photoreceptors. SEM (scanning electron microscopy) experiments were performed to identify the distribution of bacteria in leaf tissue distant from the position of bacterial cells injection [53]. This investigation revealed a much wider distribution of bacterial cells in leaf tissue, especially in apoplast regions near the xylem vessels, but only under conditions, if leaves where infiltrated with the knock-out mutants. The stronger deleterious activity of photoreceptors-devoided Pst became also evident when the hypersensitive response (HR) was followed. Observing the formation of chlorosis and of necrotic spots, when followed up to $72 \mathrm{~h}$, showed yellowing of the entire infiltrated leaf especially for the $\Delta \mathrm{LOV}$ and $\Delta \mathrm{BphP} 1$ mutants.

The related strain Pseudomonas syringae pv. syringae B728a (Pss) exhibits additional features important for plant infection and virulence, such as ice nucleation activity and production of the phytotoxin syringomycin; additionally, it can exploit both the leaf surface and the apoplast as habitats, preferentially infecting bean plants [60]. Pss has the same ensemble of photoreceptors as Pst, and, similarly to the latter organism, studies with knock-out mutants evidenced that $P s s \mathrm{BphP} 1$ attenuates spread of infection and virulence towards plants, but concomitantly favours survival of Pss immediately after leaf colonization [61]. WL represses swarming motility of Pss, an effect mainly due to RL/FRL, while this repression is counteracted by BL, underscoring a cross-talk between photoreceptors [62] already emerged with Pst [54].

Initial results with other phytopathogenic Pseudomonads indicate a role of light, possibly mediated via bacterial 
photoreceptors, in infectivity and virulence towards plants: light suppresses the population of $P$. amygdali pv. tabaci (formerly P. syringae pv. tabaci) in leaves via accumulation of reactive oxygen species (ROS), in particular $\mathrm{H}_{2} \mathrm{O}_{2}$ [63]; for P. cichorii JBC1 was demonstrated that RL and GL down-regulate infectivity towards tomato seedlings, but also in this case a link to specific photoreceptors (Table 1) remains to be identified [64].

Pseudomonas aeruginosa $(\mathrm{Pa})$ is a dangerous opportunistic human pathogen, but some strains are also capable of infecting roots causing plant mortality; it was found that formation of biofilm is a key factor for $P a$ pathogenicity [65]. Light represses biofilm formation and the expression of virulence genes, with FRL being more efficient than other wavelengths, but also BL and RL show effects [66]. This light-response proceeds via the phosphorylation of a response regulator $(\mathrm{AlgB})$ by the bathy-phy $\mathrm{PaBphP}$ and is intertwined with quorum sensing, also converging on AlgB. Recently it was reported that WL delays maturation of biofilm, indicated by wrinkling, due to low levels of c-di-GMP: this effect is most pronounced with BL, and RmcA was identified as the putative photoreceptor [67]. RmcA bears a PAS domain predicted to bind a Flavin, but lacks the reactive cysteine of LOV domains and has no resemblance to other flavin-based photosensors. The PAS domain is fused to a tandem GGDEF-EAL module (domains named after a conserved sequence motif), whereby GGDEF and EAL act potentially as a cyclase and a photodiesterase (PDE) activity regulating the turnover of c-di-GMP within the cell [68]. RmcA shows a PDE activity (EAL is active), but it is still to be demonstrated that the stimulus sensed by the PAS domain is light [67]. It should be mentioned here, however, that photoactivation of LOV domains void of the canonical cysteine has been demonstrated, with the intermediate formation of a flavin radical, indicating that apparently adduct formation is not absolutely essential to accomplish this function $[69,70]$.

An EAL sequence, however, exclusively reduced to these three amino acids without other signatures of a common EAL domain, has recently been identified within a helix between the N-terminal PAS and the GAF domain of the bathy-phy from Xanthomonas oryzae pv. oryzae (Xoo$\mathrm{BphP}$ ) and of similar proteins with the architecture PASGAF-PHY-PAS [71]. XooBphP is reported to possess PDE activity, which is higher in the dark-adapted form when the protein is in a stable Pfr state. Diverse physiological responses appear to be dependent on the light-modulated PDE function of XooBphP: the authors propose a model according to which during daylight (Pr/Pfr equilibrium) the higher levels of c-di-GMP promote formation of biofilms, EPS formation, and sessile lifestyle, thus protecting the bacteria from environmental stress. During the night or under RL (when the Pfr state accumulates) the lower level of c-di-GMP favours motility and expression of virulence factors [71]. Indeed, infection of plants with WT- Xoo showed that blight lesions are larger when bacteria are pre-incubated in the dark or under RL with respect to WL. Significantly, deletion of XooBphP or introduction of the mutation $\mathrm{C} 13 \mathrm{~A}$ (the $\mathrm{BV}$ chromophore cannot bind to $X o o \mathrm{BphP}$ ) result in reduced virulence effects of Xoo [71], somehow contrasting with the data obtained for other Xanthomonads and Pseudomonads illustrated above, for which photoreceptors seem to have a protective role towards infected plants (vide supra).

From genuine phytopathogens to bacteria being both friend and foe: Agrobacterium fabrum strain C58 (formerly Agrobacterium tumefaciens) is a good example of the latter category. A. fabrum is a soil bacterium able to live as a non-pathogenic rhizosphere colonizer or, alternatively, as a plant pathogen causing crown-gall disease. A wound on the plant can guide Agrobacterium spp. to the wounded site by diverse plant-generated compounds, among which the most important is hydroxycinnamic acid (HCA) [72]. The signalling compounds emitted by the plant are received by the bacterium through a two-component signal-system, composed of a canonical HK and RR couple, here called VirA and VirG, then starting the virulence program of the bacterium. Plant tumour development is induced by several (vir) genes, all located on a specialized tumor-inducing (TI) plasmid [73]. Approximately 30 genes are under control of a master-regulator. Upon infection, this T-region is first duplicated, then excised from the plasmid by action of an endonuclease, brought into the nucleus of a plant cell (carrying a nuclear localization signal) by a complex multi-protein process, and there randomly inserted into the plantal DNA. The bacterial DNA encodes enzymes for synthesis of auxin, cytokinin, and opine, the latter compound a nutrition source for the bacterium. The BphPs Agp1 and Agp2 from the Agrobacterium fabrum strain $\mathrm{C} 58$ have been extensively studied at the molecular level and partially in vivo [74-76]. Agp1 is a canonical BphP, where the dark-adapted state is in the $\mathrm{Pr}$ form, while Agp2 is a bathy-phy, stable in the dark as the Pfr form [77]. A starting investigation of Agp1 and Agp2 evidenced their physiological role during DNA exchange (conjugation): both BphPs positively regulate conjugation in the dark, to the extent that in the double knock-out mutant agp1-/agp2 $2^{-}$conjugation is fully inhibited [78]. Conversely, RL and FRL up-regulate conjugation (ca. 3.5 fold) in the WT strain. More important with respect to plants are the results of plant root infection: formation of root tumours by A. fabrum is strongly down-regulated by $\mathrm{RL}$, with respect to dark conditions, and almost totally

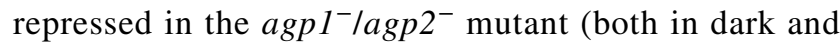
under RL) [79]. This latter result indicates that plant phyproteins, possibly present in the roots, do not have significant effects on light-regulation of tumour formation. 
Absence of Agp1 and/or Agp2 also affect swimming, inter-bacterial competition, and the expression of diverse proteins, but in many cases without light regulation [79].

Amongst the beneficial bacteria, some plant growth-promoting, nitrogen-fixing species have been investigated with respect to their photoreceptors (Table 3). The phytochrome $A b \mathrm{BphP} 1$ of the non-phototrophic Azospirillum brasilense is necessary for survival on minimal media under RL; the knock-out mutant is also more sensitive to photooxidative stress, but this protection mechanism operated by AbBphP1 is not related to carotenoid synthesis [80]. At least nine proteins are up-regulated in response to RL, among others chaperonins involved in protein refolding after photodynamic damages. Recently it was demonstrated that light is detrimental for growth and motility, with BL causing the most dramatic effects [81]. Although a link to specific photoreceptors or phototoxic molecules was not established, such observations may have an impact on the usage of this strain in agriculture.
The BL receptor R-LOV-HK of Rhizobium leguminosarum pv viciae, another nitrogen-fixing, non-phototrophic bacterium has multiple roles in this organism that all can affect root colonisation. Through this photoreceptor, BL down-regulates EPS, biofilm formation, and flagella production; furthermore, bacterial proliferation in plant roots is reduced, but the number of $\mathrm{N}_{2}$-fixing nodules is increased: these effects might be important to optimize root colonization and nitrogen fixing at different soil levels [82]. There are two more nitrogen fixing strains considered here. They belong to Bradyrhizobium spp. that express photosystems and grow as phototrophs [83]: Bradyrhizobium is especially important in agriculture, given that commercial legumes can establish symbiosis with species belonging to this genus [84]. In some countries, Bradyrhizobium strains are even used as inoculant to optimize soybean productions [85, 86]. This genus comprises three main phylogenetic supergroups represented by $B$. japonicum, B. elkanii, and the photosynthetic Bradyrhizobium species/strains [87]. Among

Table 3 Photoresponses in plant associated bacteria

\begin{tabular}{|c|c|c|}
\hline Species & Light/photoreceptor regulation & Photoreceptor \\
\hline \multirow[t]{2}{*}{ Agrobacterium fabrum } & Dark up-regulates and RL/FRL down-regulate conjugation [78] & Agp1;Agp2 \\
\hline & WL inhibits tumor formation [79] & - \\
\hline \multirow[t]{2}{*}{ Azospirillum brasilense } & BL/WL inhibit growth and swimming motility [81] & - \\
\hline & Control of photodynamic stress and survival in RL [80] & $A b \mathrm{BphP} 1$ \\
\hline Bradyrhizobium sp. ORS278 & FRL enhances photosystem synthesis [89] & $B r \mathrm{BphP} 1$ \\
\hline Bradyrhizobium sp. BTAi1 & RL/FRL control synthesis of peripheral LH complex synthesis [91] & BphP3B BTAi1 \\
\hline Bacillus amyloliquefaciens & $\begin{array}{l}\text { RL/GL enhance growth and production of lipopeptide; BL supresses } \\
\text { bacterial growth }[93,94]\end{array}$ & - \\
\hline Bacillus thuringiensis & Strong photoreactivation of UV-induced DNA damages [96] & PHR \\
\hline \multirow[t]{2}{*}{ Pseudomonas aeruginosa } & WL represses biofilm formation and virulence [66] & $P a \mathrm{BphP}$ \\
\hline & WL/BL inhibit biofilm wrinkling [67] & $\mathrm{RmcA}^{\mathrm{a}}$ \\
\hline Pseudomonas amygdali pv. tabaci & WL supresses bacteria population in leaves via ROS [63] & - \\
\hline Pseudomonas cichorii & RL and GL down-regulate infectivity [64] & - \\
\hline \multirow[t]{3}{*}{ Pseudomonas syringae pv. tomato } & $\begin{array}{l}\text { Negative regulation of virulence and leaf colonization, down-regula- } \\
\text { tion of swarming motility }[8,53,54]\end{array}$ & PssBphP1; PssBphP2; PssLOV \\
\hline & RL enhances bacterial of growth into leaves [191] & PssBphP1 \\
\hline & $\begin{array}{l}\text { RL enhances resistance of tomato plants to Pst [58] } \\
\text { RL delays the programmed death of infected tobacco leaves [59] }\end{array}$ & - \\
\hline \multirow[t]{2}{*}{ Pseudomonas syringae pv. syringae } & RL/FRL/WL repress swarming motility, counteracted by BL [62] & PssBphP1; PssLOV \\
\hline & $\begin{array}{l}\text { Negative regulation of virulence and leaf colonization; enhancement } \\
\text { of survival immediately after leaf colonization [61] }\end{array}$ & PssBphP1 \\
\hline Rhizobium leguminosarum pv. viciae & $\begin{array}{l}\text { BL inhibits bacterial proliferation, EPS, biofilm and flagella forma- } \\
\text { tion; promotes formation of } \mathrm{N}_{2} \text { fixing nodules [82] }\end{array}$ & R-LOV-HK \\
\hline Xanthomonas campestris pv. campestris & $\begin{array}{l}\text { WL/FR negatively regulate virulence, virulence factors, xanthan } \\
\text { production, biofilm maturation [50] }\end{array}$ & $X c c \mathrm{BphP}$ \\
\hline Xanthomonas citri subsp. citri & $\begin{array}{l}\text { Negatively regulates virulence, motility and EPS formation; pro- } \\
\text { motes flagellum formation and adhesion to leaves }[7,192]\end{array}$ & $X c c \mathrm{LOV}$ \\
\hline Xanthomonas oryzae pv. oryzae & $\begin{array}{l}\text { Light/dark control of motility, infectivity, and virulence factors via } \\
\text { tuning c-di-GMP levels [71] }\end{array}$ & ХоoBphP \\
\hline
\end{tabular}

${ }^{-}$: indicates that the photoreceptor(s) responsible for a given photoresponse has (have) not been identified

${ }^{\text {a }}$ Photoreactive cysteine is missing 
symbiotic bacteria, Bradyrhizobium sp. ORS278 is a special case emphasising the close relationship with the host plant as for photosensing. In this organism the first bathy-phy named $B r \mathrm{BphP} 1[88]$ was discovered: $B r \mathrm{BphP} 1$ controls the synthesis of the photosynthetic system, up-regulated by FRL with a maximum efficiency at $750 \mathrm{~nm}$ [89]. Beyond a canonical $\mathrm{BphP}$ (BrphP2), this bacterium also bears a PCB binding module with $\lambda_{\max }=610 \mathrm{~nm}$. The encoding gene was inherited by horizontal gene transfer (HGT) together with the enzymatic apparatus to synthesize the chromophore, which, similar to the phytochromes from plants and cyanobacteria, is bound to a cysteine within the GAF domain; this special photoreceptor, with unknown functional role, is switching between a dark-state absorbing in the orange range $(\mathrm{Po})$ and a photoactivated red absorbing form (Pr) with an absorption maximum around $670 \mathrm{~nm}$ [90]. In the related Bradyrhizobium sp. BTAi1, the RL/FRL ratio controls the synthesis of the peripheric light harvesting complex [91]. Both strains are phototrophic and are equipped with three BphPs, one LOV protein, and one/two BLUF photoreceptors (Tables 1, Table S1). This is in sharp contrast with the non-photosynthetic rhizobia discussed above, and even with $B$. japonicum which solely possesses a gene for a BphP, no LOV and no BLUF proteins [10]. These observations, together with the few experimental data available, suggest that in nitrogen fixing, root nodulating bacteria at least some photoreceptors are linked to phototrophic life. A similar suggestion has been recently made for Methylobacteria that mostly reside in the phyllopshere, possess photosystems, and are packed with photoreceptors, with the exception of $M$. nodulans that colonizes roots and has no photosynthetic potential [18]. An important difference with Bradyrhizobia does exist, though: $M$. nodulans has given up (or not acquired) BL receptors, but BphPs.

To conclude this section dedicated to bacteria we briefly mention the few known light-effects on the gram-positive, non-phototrophic Bacillus amyloliquefaciens and Bacillus thuringiensis. The former is associated to roots, acts as biofertilizer through nitrogen fixation and phosphate solubilisation, and can control infections by producing a lipopeptide toxin and by triggering plant defense responses against phytopathogens [92]. Recently it was shown that RL/GL enhance bacterial growth and production of the lipopeptide, while BL supresses bacterial growth $[93,94]$. The only photoreceptor candidate for the latter response is a LOV protein, analog to B. subitlis YtvA [95], but a physiological link was not established; alternatively, BL growth suppression can be a phototoxic effect. Interestingly, B. amyloliquefaciens has no genes encoding for Cry/PHR proteins and, accordingly, does not show photoreactivation of UV-induced damages to DNA [96]. On the contrary, a strong photoreactivation is observed for B. thuringiensis [96]. This bacterium produces insecticidal toxins during the sporulation phase of growth and is, therefore, used in agriculture and in transgenic plants as a biocontrol agent [97].

\section{Photoresponses and photoreceptors in plant-associated fungi}

Given the prominent role that light has on the life cycle of fungi, we present an image illustrating as a paradigm the reproduction and morphogenesis patterns of the filamentous plant pathogen Botrytis cinerea (Botryotinia fuckeliana), an ascomycete that is the causal agent of grey mould disease in many agricultural plants [98]. B. cinerea has a a necrotrophic lifestyle, attacks all aerial parts of a plant and also rotting fruits, producing grey conidiophores and conidia typical of the diseases (Fig. 3).

Filamentous fungi colonize plant tissue in the form of vegetative mycelia and, for dispersal and survival, they produce conidiospores (asexual) and ascospores (sexual); in this fungus light serves as an important cue for making lifestyle decision [99]. Studies with A. thaliana evidenced that $B$. cinerea penetrates the plant during night (dark), in the form of a vegetative mycelium [22]. The evolution of the mycelium into conidia (asexual reproduction) for dispersal (summer cycle) or into a hard mass called sclerotium (winter cycle) is determined by light quality and quantity. The sclerotia are formed only in constant darkness and they are meant for survival, since they mostly germinate asexually giving origin to mycelia and conidia; but sclerotia are also a prerequisite for sexual reproduction: when in spring they meet microconidia of the opposite mating type, they are fertilized and, in the light, they give origin to the sexual structures (apothecia). Formation of sclerotia is inhibited by WL and BL. Light is, therefore, a cue to decide between two choices: dispersal by formation of the asexual conidia in the light, or survival in the dark by forming sclerotia [100]. Formation of conidia is stimulated by WL, near UV, and FRL, while it is inhibited by RL and BL. BL thus ultimately inhibits development both of sexual or asexual spores [100]. Further photoresponses of $B$. cinerea include positive phototropism of conidiophores towards BL and negative phototropism of conidial germ tubes [101]. The complex array of photoresponses in B. cinerea relies on a large number of photoreceptors (Table 2 and Table S2) [100], whose known roles will be discussed later in this section.

Much of the molecular and physiological information on fungal light response derives from studies with the saprophytic ascomycetes Neurospora crassa and Emericella nidulans (Aspergillus nidulans). In $N$. crassa the clock proteins White Collar 1 and 2 (WC-1 and WC-2) interact to form the transcriptional factor White Collar Complex (WCC) that in its dimeric forms promotes the expression of target genes with a circadian rhythmicity [102]. Among 
Fig. 3 Life cycle of B. cinerea and influence of light. Sclerotia are vegetative structures formed in the dark, but also a prerequisite for fertilization and sexual reproduction. Note that the sexual structures (apothecia) need light to develop. Asexual reproduction via conidia is prompted by WL, FRL, and UV light, while RL and BL are negative factors. Adapted from ref. [100]

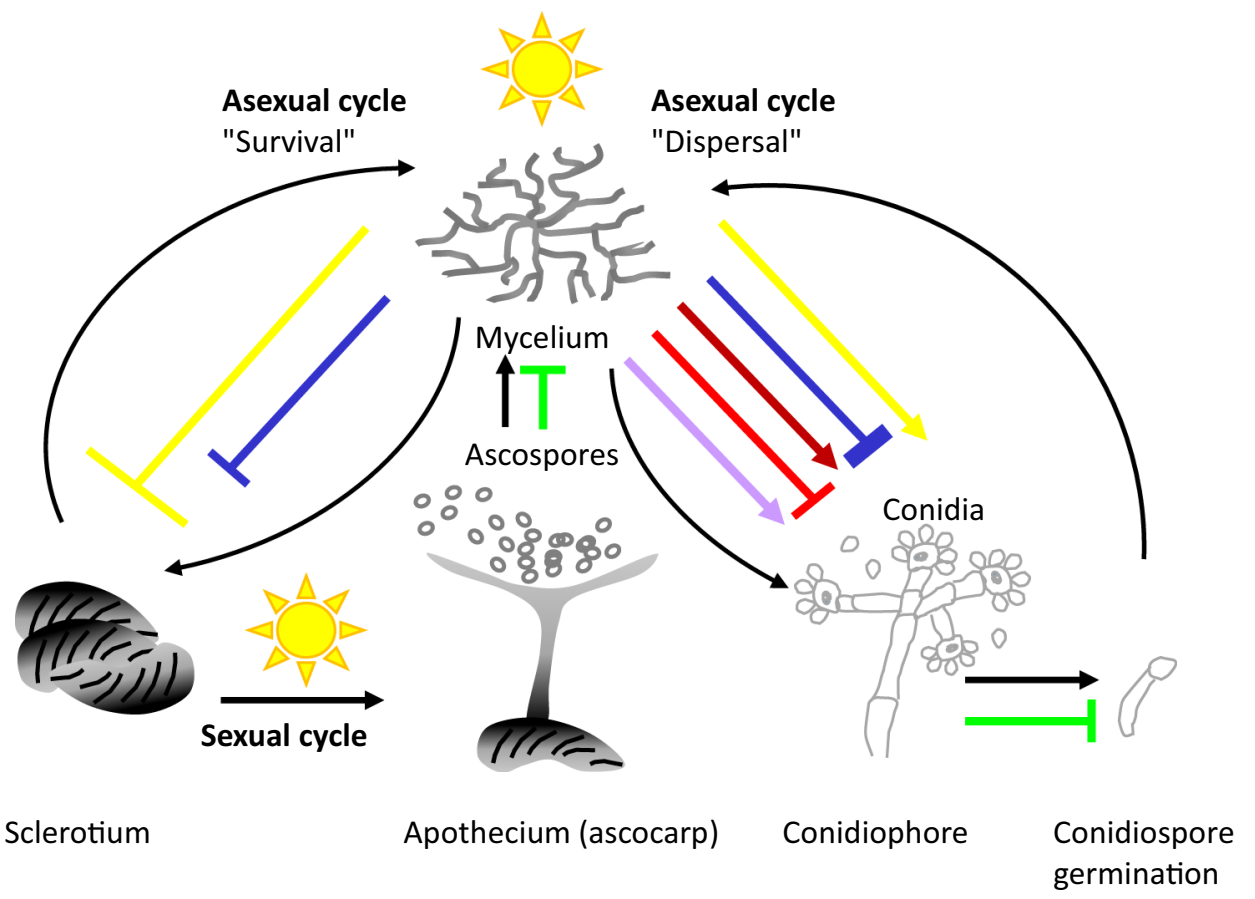

conidiation (asexual reproduction) occurs under $\mathrm{BL}$ and $\mathrm{O}_{2}$ [110]. In addition, photoactivated ENV1 inhibits pheromone production and female fertility in the light [111].

The physiological roles of the other photoreceptors of $N$. crassa are less characterized, but available data give some promising hints: the phytochrome PHY-2 was recently shown to participate in the light-induced repression of sexual reproduction [112], while no clear function has been assigned to the Cry protein [105]. During sexual development the expression of the $N$. crassa rhodopsin (NOP-1) is upregulated; an extended transcriptomic analysis strongly indicates that NOP-1 act in concert with oxidative stress to inhibit sexual development, through its GL-driven protonpumping activity [113].

The saprophyte E. nidulans is used since many years as a model for cross-talk among multiple photoreceptors, where mainly RL regulates development and metabolite production [105]. Although normally not associated to plants, E. nidulans is closely related to phytopathogens and mycotoxin producers [5]. Light effects are mediated by a complex network, where the main actors are the phytochrome FphA, the LreA/ LreB complex (orthologue of $N$. crassa WCC, LreA is an LOV protein) and VeA, a master regulator of development and secondary metabolism; these proteins form a complex in the nucleus [114]. Both BL and RL upregulate conidia formation and repress ascocarps (cleistothecia) production, but the largest inhibitory effect is found under RL via FphA, while the LreA/LreB complex is suggested to have a positive effect. Light exerts a similar inhibitory effect on the synthesis of the mycotoxin sterigmatocystin, again mainly via FphA, while LreA/LreB has again a stimulatory function with other signal transduction chains; indeed, BL-induced 
Fig. 4 In the circadian clock of $N$. crassa WC-1 and WC-2 form the transcriptional factor WCC, that promotes expression of many genes, among which also the clock protein FRQ and for VVD. As FRQ and VVD accumulate, they inhibit WCC, generating feedback loops ( adapted from ref. [23]). Photoadaptation provided by VVD is based on competitive homo-heterodimeration. In T. reesei (dotted forms) the VVD-like protein ENV1 is involved also in protection against oxidative stress: under these latter conditions ENV1 is sequestered in a dimeric form, competitive with its interaction with the WCC complex that remains active [110]. Additionally BL represses pheromone synthesis [111]
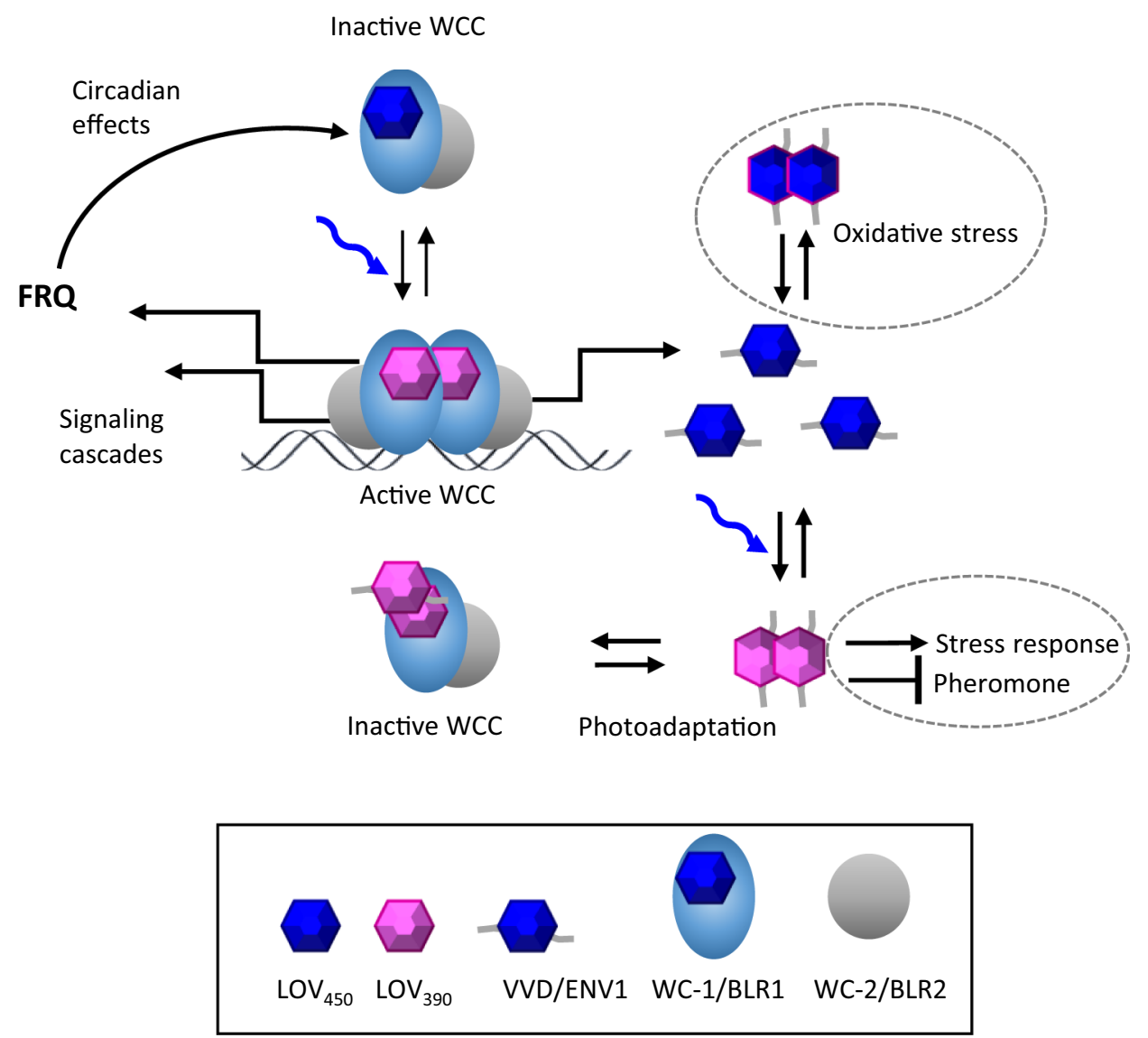

[115]. Most interestingly and indicative of FphA photochromicity and activity is the fact that RL-induced conidiation is reversed by FRL $[116,117]$. FphA is also involved in temperature, osmolarity, and stress sensing signalling [118, 119]. Through FphA, light upregulates NO levels and the expression of agaA (arginase) and $f h b B$ (flavohaemoglobin B) [120]. The multiple effects of FphA are mediated and fine-tuned by interactions with the LreA/LreB complex and with VeA [115]. Recently, a global regulator, possibly involved in light-induced chromatin remodelling and interacting with FphA, was identified and named RlcA (regulator of light sensing and chromatin remodelling) [121]. The WC-1 like protein LreA acts mainly as a BL-triggered inhibitor of sporulation [122], while LreB physically interacts with FphA [115]. Not withstanding the major role played by FphA in light regulation, the key enzyme for BV production, heme oxygenase, has not yet been found in this fungus [123].

A similar light regulation as in E. nidulans has been described for Alternaria alternata, a food contaminant and plant pathogen causing leaf spots, rots, and blights on many plant parts, producing diverse health-endangering mycotoxins, e.g., alteraniol and altertoxins [124, 125]. BL inhibits asexual sporulation, while RL reverses this effect underscoring interplay between different photoreceptors with LreA taking a prominent role; deletion mutants in FphA and LreA showed a reduced sporulation in the dark, suggesting also light-independent roles for these photoreceptors: in the $f p h A$ mutant conidiation was reduced by $86 \%$ in the dark with respect to the WT strain [126]. The deletion mutants lreA and fpha also showed the highest degree of resistance to oxidative stress, independent of light, due to upregulations of catalase and superoxide dismutase, indicative of crosstalks with other stress sensing systems. Both RL and BL sensing are in close interplay with high-osmolarity glycerol (HOG) mitogen-activated protein (MAP) kinase pathway. Importantly, BL and GL stimulate production of the mutagenic toxin alternariol, an effect due to the LOV protein LreA [126]. Until now it was not possible to detect any light effect on the virulence of A. alternata, an aspect particularly relevant, because Alternaria species cause at least $20 \%$ of crop losses of all fungal-mediated diseases, as it infects a broad variety of agricultural plants [125].

This observation brings us back to the phytopathogen $B$. cinerea. This filamentous fungus carries genes enconding for three phy proteins (Bcphy1, Bcphy2, Bcphy3), four LOV proteins ( $B c$ wcl1, $B c$ vvd1, Bclov3, BcLOV4), two Cry/PHR (Bccry1, Bccry2), and two rhodopsins (Bop1, Bop2). Bcwcl1 is WC-1-like LOV protein with a $\mathrm{Zn}$-finger domain, making part of the WCC complex with $B c w c l 2$. A basic function of this $\mathrm{BL}$ photoreceptor is repression of both conidia 
and sclerotia development; furthermore, it is crucial for light-induced transcription of genes encoding for the other photoreceptors, for enzymes in the carotenogenesis pathway, for stress proteins, and for transcription factors [22]. More than 400 genes are regulated in BL by the action of the WCC complex and related transcription factors [127]. Another BL receptor essential for light-repression of conidiation is $B c$ Cry2, while $B c$ Cry 1 acts as a PHR [128]. The WCC complex is also required for coping with excessive light, oxidative stress, and for achievement of full virulence towards plants [127]. Many of the light responses mediated by the WCC complex rely on the transcription factor $B c$ LTF1, especially important to cope with the oxidative stress caused either by light or by the plant defence response during infection [129]. Out of the three phy proteins, $B c$ phy 3 is required for normal sclerotia formation, vegetative growth and phytopathogenicity, although the role of RL/FRL is not clear [130]. As mentioned above, RL represses and FRL promotes conidiation, pointing to the photochromicity typical of phytochromes (Fig. 3). Importantly, FR reduces resistance to $B$. cinerea but increases fruit mass in tomato, indicative of the double aspect of light during plant-pathogen interaction [131]. Although many aspects of the light-life of $B$. cinerea remains to be clarified at the molecular level, it is clear that this organism is becoming a model to understand the role of light and fungal photoreceptors during plant-pathogen interaction. Recently a LOV protein containing a RGS (regulator of G-protein signaling) domain has been identified in $B$. cinerea and other fungi (Table S2), indicated as BcLOV4 [37]. These fungal RGS-LOV proteins are associated with anionic plasma membrane phospholipids, when photoactivated with BL [132], and are now being used to engineer systems for optogenetic applications [133].

Other well-known phytopathogens and mycotoxin producers are members of the Fusarium genus [134] that includes four species complexes for which light regulation has been investigated (Table 4): (i) F. asiaticum and $F$. graminearum strains which cause head blight in wheat, barley, and other small grain cereals $[135,136]$. (ii) F. fujikuroi strains that cause the bakanae disease in plants by producing the phytohormone gibberellin. As a consequence, the plants grow long without control and eventually die; F. fujikuroi can also contaminate maize and other cereals through the production of fumonisin mycotoxins [137]. (iii) F. oxysporum strains, root associated fungi that can be pathogenic, neutral or even beneficial for fighting other plant infections [138]. As they are known to infect the roots of more than 100 agronomical plants, $F$. oxysporum phytopathogenic strains cause extensive damages, from wilting to necrosis, to an extent that they are ranked among the top 10 fungal phytopathogens as for their economic importance. Many Fusarium strains are also opportunistic pathogens for animals including humans [139].
In contrast to the situation in E. nidulans (see above), the phytochrome of $F$. graminearum, $F g F p h$, does not play a role in the sexual development of this organism, while the WCC complex $(F g \mathrm{Wc}-1 / F g \mathrm{WC}-2)$ acts as a negative factor for perithecia formation and has a positive effect on photoreactivation [140]. The observed effects on sexual development are quite puzzling, because light has, as a whole, a positive effect on this process. Other light effects in $F$. graminearum are the upregulation of carotenoid synthesis (by BL) and the down-regulation of trichothecene mycotoxins production [141]. In the related $F$. asiaticum, BL upregulates carotenoids and induces UV-C resistance, while FaWC- 1 is required for sexual fruiting body maturation and ascospore formation [142]. BL has a positive effect also in F. fujikuroi on carotenoid production, via VvdA, WcoA (WC-1), possibly involving activity of the phy protein PhyA [143, 144]. In this organism, the synthesis of the green pigment bikaverin is repressed by a cryptochrome (CryD) [145], and one of the two rhodopsins, the proton pumping $\mathrm{CarO}$, retards spore germination from light-formed conidia in a GL-dependent manner [146]. Importantly, the pumping activity of CarO is enhanced by a plant hormone, the auxin indole-3-acetic acid (IAA); the presence of $\mathrm{CarO}$ also strongly diminishes the severity of disease symptoms and the expression of this photoreceptor is strengthened by light, also when the fungus has already entered the plant [147]. To finish with this genus, in F. oxysporum f. sp. lycopersici, BL upregulates expression of photolyase and carotenoids; the BL receptor WC-1 does not affect pathogenicity on plants, but is required for infecting animals [148]. Recently it was reported that during infection of plants WL/BL sharply increase ethylene production in B. cinerea, F. asiaticum, A. alternata, and other pathogenic fungi. The authors have proposed to exploit this phenomenon for non-invasive detection of fungal infections [149].

Many phytopathogenic fungi produce photosensitisers, such as hypocrellin and cercosporin that act as photoactivated phytotoxins [150]. A well-known example is Cercospora zeae-maydis, the causal agent of gray leaf spot in maize [151]. In this fungus BL represses conidiation, upregulates cercosporin synthesis and photolyase expression via the LOV proteins CRP1 (WC-1); CRP1 is also essential for tropism towards stomata and induction of foliar necrosis [152]. Therefore, for C. zeae-maydis a BL receptor of the LOV superfamily is strictly correlated with its pathogenic effects towards plants and, again, upregulation of PHR hints to enhancement of photoprotection.

Further light regulation has been described in other phytopathogenic Ascomycota. In Colletotrichum acutatum, causal agent of the destructive anthracnose in many agricultural plants [153], RL/GL reduce mycelial growth, while BL impairs conidial germination, enhances virulence against pepper, and the amount of melanin [154]. 
Table 4 Photoresponses in phytopatogenic and model fungi

\begin{tabular}{|c|c|c|}
\hline Species & Light/photoreceptor regulation & Photoreceptor \\
\hline Alternaria alternata & $\begin{array}{l}\text { BL inhibits sporulation, RL reverses this effect; BL/GL up regulate the mycotoxin } \\
\text { alternariol; photoreceptors diminish resistance to ROS [126] }\end{array}$ & LreA (WC-1) FphA \\
\hline \multirow[t]{5}{*}{ Botrytis cinerea } & $\begin{array}{l}\text { BL represses conidiation and sclerotia development. Increases resistance to (photo) } \\
\text { oxidative stress and virulence; light regulation of }>400 \text { genes among which those } \\
\text { for the } 11 \text { photoreceptors, carotenoid synthesis and for conidiation }[22,127]\end{array}$ & $B c \mathrm{WCL} 1(\mathrm{WC}-1)$ \\
\hline & BL repression of conidiation[128] & BcCry2 \\
\hline & $\begin{array}{l}\text { RL represses and FRL promotes conidiation; BL represses conidiation; GL represses } \\
\text { growth of mycelia [100]; BL promotes phototropism of conidiophores [101] }\end{array}$ & \\
\hline & FR reduces resistance to $B$. cinerea but increases fruit mass in tomato [131] & \\
\hline & Promotes sclerotia formation, vegetative growth and pathogenicity [130] & Bcphy3 \\
\hline Cercospora zeae-maydis & $\begin{array}{l}\text { BL represses conidiation, upregulates the light-activated toxin cercosporin and PHR; } \\
\text { CRP1 is essential for tropism towards stomata and induction of foliar necrosis } \\
\text { [152] }\end{array}$ & CRP1 (WC-1) \\
\hline Colletotrichum acutatum & $\begin{array}{l}\text { RL/GL reduce mycelial growth; BL impairs conidial germination, enhances viru- } \\
\text { lence and amount of pigments [154] }\end{array}$ & $?$ \\
\hline Emericella nidulans & $\begin{array}{l}\text { RL and BL favour asexual reproduction and inhibit sexual reproduction via FphA; } \\
\text { LerA favours sexual reproduction [115] } \\
\text { BL, RL and FRL delay conidiospore germination[118] } \\
\text { WL represses production of the mycotoxin sterigmatocystin; FphA inhibitor, LreA } \\
\text { stimulator [115] } \\
\text { FphA involved in temperature sensing, osmosensing and stress-sensing signalling } \\
\text { [118, 119] } \\
\text { WL upregulates NO; FphA upregulates and LreA represses agaA and fhbB }{ }^{\mathrm{a}} \text {. The } \\
\text { global nuclear regulator RlcA interacts with FphA [121] }\end{array}$ & FphA LreA (WC-1), \\
\hline Fusarium asiaticum & $\begin{array}{l}\text { BL upregulates carotenoids and induces UV-C resistance; } F a \mathrm{WC}-1 \text { required for } \\
\text { sexual fruiting body maturation and ascospore formation [142] }\end{array}$ & $\mathrm{FaWC}-1$ \\
\hline \multirow[t]{5}{*}{ Fusarium fujikuroi } & BL upregulates carotenoids and affects mycelial development [143] & VvdA \\
\hline & $\begin{array}{l}\text { BL upregulates carotenoids [144]; CryD represses the synthesis of the pigment } \\
\text { bikaverin and the production of macroconidia [145] }\end{array}$ & CryD, WcoA (WC-1) \\
\hline & RL upregulates carotenoids [144] & PhyA (?) \\
\hline & $\begin{array}{l}\text { GL retards spore germination from light-formed conidia [146]; pumping activity } \\
\text { enhanced by IAA [147] }\end{array}$ & $\mathrm{CarO}$ \\
\hline & No pumping activity, unknown function [147] & OpsA \\
\hline Fusarium graminearum & $\begin{array}{l}\text { WL required for sexual development; FgWc-1 negatively regulate sexual develop- } \\
\text { ment and favours photoreactivation; BL upregulates carotenoids; light represses } \\
\text { production of a mycotoxin }[140,141]\end{array}$ & FgWc-1, FgFph? \\
\hline $\begin{array}{l}\text { Fusarium oxysporum } f \text {. } \\
\text { sp. lycopersici }\end{array}$ & $\begin{array}{l}\text { BL upregulates PHR and carotenoids; WC-1 does not affect pathogenicity in plants, } \\
\text { is needed for infecting animals [148] }\end{array}$ & WC-1 \\
\hline Magnaporthe oryzae & Light-dependent disease suppression during the dark-phase [156] & MGWC-1 \\
\hline \multirow[t]{4}{*}{ Neurospora crassa } & $\begin{array}{l}\text { Clock protein; forms with WC-2 the WCC transcription factor; BL upregulates } \\
\text { carotenoids [23] }\end{array}$ & WC-1 \\
\hline & Downregulates carotenoids; [106]photoadaptation via WCC sequestration [104] & VVD \\
\hline & Contribute to repression of sexual development in the light [112] & Phy-1, Phy-2 \\
\hline & $\begin{array}{l}\text { Contribute to repression of sexual development in the light; coupling with oxidative } \\
\text { stress [113] }\end{array}$ & NOP-1 \\
\hline \multirow[t]{4}{*}{ Ustilago maydis } & GL-driven proton pumps [164] & UmOps1,UmOps2 \\
\hline & Highly expressed during corn infection [165] & UmOps3 \\
\hline & $\begin{array}{l}\text { WL/BL/RL stimulation of basidiocarps (sexual reproduction) formation, with RL } \\
\text { more effective than BL; Phy1 needed to form basidiocarps [163] }\end{array}$ & Wco1a (WC-1), Wcolba ; Phy1 \\
\hline & $\begin{array}{l}\text { BL-induction of }>50 \text { genes via WC- } 1 \text { among which Cry/PHR proteins contributing } \\
\text { to UV tolerance [162] }\end{array}$ & Wcola (WC-1) \\
\hline Venturia inaequalis & NIRL stimulates spore release [158] & $?$ \\
\hline Zymoseptoria tritici & $\begin{array}{l}\text { WL, RL and BL affects largely gene expression; upregulation of Cry, NOP-1, and } \\
\text { genes for oxidative stress, metabolism and transportation [160] }\end{array}$ & $?$ \\
\hline
\end{tabular}

${ }^{\mathrm{a}}$ : agaA arginase, $f h b B$ flavohaemoglobin B 
In Magnaporthe oryzae, the causal agent of rice blast [155], it was observed that the BL receptor MGWC-1 is responsible for disease suppression during the dark-phase in alternating light-dark cycles; this occurs immediately after host-pathogen contact [156]. Venturia inaequalis causes apple scab worldwide [157]. In this fungus, near infrared light (NIRL) stimulates spore release, an important step for disease spread; importantly, artificial illumination during the night resulted in an increase of almost $50 \%$ of released ascospores [158]. The photoreceptor responsible for these effects has so far not been identified. Zymoseptoria tritici is one of the most damaging pathogen of wheat worldwide [159]. In Z. tritici WL, RL, and BL largely affect gene expression: the genes for the photoreceptors Cry and NOP-1 (rhodopsin) are upregulated by light, as well as those for oxidative stress, metabolism, and transportation [160].

The sole phytopathogenic basidiomycete for which photoreceptors and photoresponses have been characterized is Ustilago maydis, the causal agent of corn smut disease in maize. This organism is often used as a model system for fungi-plant interaction [161]. U. maydis has a biphasic lifestyle: as a saprophyte it shows a yeast-like morphology and is haploid, but on a suitable surface and under the influence of pheromones two cells can fuse (sexual reproduction) and the resulting diploid is the pathogenic form that grows as a filamentous fungus [161]. The fruiting body (sexual structure) is named basidiocarp. U. maydis is equipped with one LOV protein (Wco1a), one phytochrome (Phy1), one BLUF protein (Blf1), two photolyases (PHR1, PHR2), two cryptochrome (Cry1, Cry2), and three rhodopsins (UmOps1, UmOps12, UmOps3) (Table S2). More than 50 genes are induced by BL via the WC-1 protein Wcola, among which Cry/PHR proteins contribute to UV tolerance [162]. WL/ BL/RL stimulates formation of basidiocarps, with RL being more effective than BL; indeed, Phy 1 is needed to form basidiocarps, also independent of light [163]. The first two rhodopsins are GL-driven proton pumps [164], while $U m \mathrm{Ops} 3$ is highly expressed during corn infection, therefore, considered to be an important photoreceptor for this process [165]. Quite unfortunately, the function of Blf1 is not known [9, 162], as BLUF photoreceptors are quite rare in plant-associated fungi.

Tuber spp. comprise hypogeous ascomycetes that can form a symbiosis with plant roots, the ectomycorrhizae [166], and can become parasite of non-ectomycorrhizal plants [167]. Tuber melanosporum and Tuber borchii possess genes encoding canonical WC-1/WC-2 systems sensing BL and genes for phy proteins (Table 2, TS2). In both fungi, BL inhibits mycelial growth, a key feature of symbiosis establishment, while the phytochromes were reported to be non-functional (Table 5) [168, 169].

Sordaria fimicola is a dung fungus, normally non phytopathogenic that can live as endophyte and reduce growth and fecundity of plants [170]. In S. fimicola BL effects via SfWC-1 include phototropism and carotenoids synthesis, regulation of rhythmic zonation of ascocarps and of fruitingbody development [171].

Some fungi associated to plants are entomopathogenic, i.e., they parasitize insects that damage plants and are thus considered beneficial as biocontrol agents and probiotics [172-174]. Taking Metarhizium robertsii as an example, this fungus is insect-pathogenic, establishes mutualistic

Table 5 Photoresponses in plant-associated, non phytopathogenic fungi

\begin{tabular}{|c|c|c|}
\hline Species & Light/photoreceptor regulation & Photoreceptor \\
\hline \multirow[t]{2}{*}{ Beauveria bassiana } & BL upregulates conidiation; VVD serves for virulence towards insects [178] & VVD \\
\hline & $\begin{array}{l}\text { RL/FRL down-regulate conidiation. Regulates growth, conidiation and multistress tolerance; } B b \text { phy } \\
\text { diminishes resistance to ROS [179] }\end{array}$ & Bbphy \\
\hline \multirow[t]{2}{*}{ Cordyceps militaris } & BL upregulates conidia, carotenoids and cordycepin & $\mathrm{CmWC}-1$ \\
\hline & BL upregulates cordycepin and downregulates carotenoids [182] & $C m \mathrm{VVD}$ \\
\hline Metarhizium acridum & WL upregulates PHR and increases photoreactivation ability [176] & $?$ \\
\hline Metarhizium robertsii & $\begin{array}{l}\text { WL, BL, GL, RL influence resistance of conidia to osmotic stress and to UV. Conidia formed in the } \\
\text { dark are more resistant [174] }\end{array}$ & \\
\hline Sordaria fimicola & $\begin{array}{l}\text { BL induces phototropism and carotenoids; regulation of rhythmic zonation of ascocarps and fruiting- } \\
\text { body development [171] }\end{array}$ & SfWC-1 \\
\hline \multirow[t]{2}{*}{ Trichoderma atroviride } & BL induces conidiation [185] & BLR1 (WC-1) \\
\hline & PHR-like action; BL and RL regulation of gene expression [186] & CRY1 \\
\hline Trichoderma harzianum & BL induces expression of PHR1 and of pigmented, resistant spores [187] & \\
\hline \multirow[t]{2}{*}{ Trichoderma reesei } & $\mathrm{BL}+\mathrm{O}_{2}$ induce conidiation $[110]$ & BLR1 (WC-1) \\
\hline & $\begin{array}{l}\text { Integrates BL, redox and nutrient sensing and photoadaptation; regulates growth and pheromone } \\
\text { production, needed for female fertility in the light[111] }\end{array}$ & ENV1 \\
\hline Tuber borchii & BL inhibits mycelial growth [168] & Tbwc-1 \\
\hline Tuber melanosporum & BL inhibits mycelial growth [169] & $?$ \\
\hline
\end{tabular}


interactions with plants and stimulates plant root development [175]. In this organism light (WL, BL, GL or RL) influences resistance of conidia to osmotic stress and to UV, i.e., conidia formed in the dark are more resistant [174]. In the related $M$. acridum, WL upregulates expression of a photolyase and increases photoreactivation ability [176]. Scientific reports for these fungi are still sporadic and lighteffects have not been related to any specific photoreceptor. The entomopathogen Beauveria bassiana is being increasingly used to control insect pests in the field and is under inspection for its ability to promote plant growth, the possibility that strong inoculation of its spore at the roots level might affect the plant microbiota and for the question of its persistence in the environment [177]. In B. bassiana BL upregulates conidiation and, importantly, the BL sensor VVD is required for virulence towards insects [178]. RL/ FRL instead down-regulate conidiation and the Blphy photoreceptor participates in growth, conidiation and multistress tolerance; interestingly the presence of Bbphy diminishes resistance to ROS [179].

The ascomycete Cordyceps militaris is under investigation especially for its ability to produce cordycepin, a potent herbicide that inhibits plant growth, and as an entomopathogen [180]. In C. militaris light controls the expression of more than 1000 genes, almost $60 \%$ of which via the LOV protein $\mathrm{Cm}$ WC-1 [181]. Genome inspection revealed the existence of other five photoreceptor candidates (Table 2 and Table S2): one phytochrome, one LOV-domain protein, $C m V V D$, and three members of the CRY/PL superfamily [182]. Inactivation of the gene for $C m W C-1$ results in impaired production of conidia, carotenoid and cordycepin, as well as morphological modification of hyphae [181]. $C m$ VVD has thus a role both in photoadaptation (as in $N$. crassa) and in the BL-induced upregulation of $C m \mathrm{WC}-1$; furthermore, $C m V V D$ has a positive effect on cordycepin synthesis, while it downregulates the production of carotenoids [182].

Fungi belonging to the genus Trichoderma are used in agriculture as biocontrol agents against other, pathogenic fungi and also because they participate in preserving plant health and protection against infections [24]. Trichoderma reesei is an endophyte that promotes the growth of the wheat Solanum surattense under salt stress [183]. T. reesei represents a model organism, because it exhibits a large variety of physiological phenomena. It has been found, as an example given, to degrade plant cell walls and is even employed in industry for the production of cell wall degrading enzymes [184]. In addition, and most interesting for this paper, it shows quite a range of light-induced responses: $\mathrm{BL}$ induces conidiation when oxygen is present, a response mediated by BLR1 (WC-1) [110]. As mentioned above, the VVD-like protein ENV1 integrates BL, redox, and nutrient sensing with photoadaptation; ENV1 also regulates growth and pheromone production, needed for female fertility in the light [111]. In T. atroviride $\mathrm{BL}$ also induces conidiation via BLR1 [185]. In this fungus the photoreceptor CRY1 has a PL-like action, but also regulates the expression of genes in a BL- and RL-dependent way [186]. The RL-effect observed for the Cry protein in T. atroviride appears contradictory; however, RL regulation has been previously reported for a CRY protein from the green alga Chlamydomonas reinhardtii and this effect has been ascribed to the presence of neutral radical state of the bound flavin chromophore [43]. Finally, in T. harzianum BL induces expression of the photolyase PHR1 and of pigmented, resistant spores [187].

\section{Conclusions and perspectives}

Entering the field of plant-microbe interactions revealed a multi-faceted research area exhibiting variations of this interplay ranging from probiotic over symbiotic up to clearly plant pathogenic scenarios; on top, some of these microbes are also known as animal-/human-pathogens. This research is growing, but currently still in its infancy, partially due to the often missing molecular characterization of the individual photoreceptor proteins, not to speak of only sparse information on the interaction of the plant-dwelling microbes and their plant hosts. The lack of information, but also the wealth of data extracted from genome-wide surveys, as performed here, allow stunning and intriguing insights into this complex plant-microbes network. Considering the large number of bacteria and fungi carrying photoreceptors, intense work is required, as some of these microbes have been identified to cause significant economic loss.

Information on bacterial photoreceptors, their function and biochemical properties, and their impact on the bacterial behavior and plant-directed activity is more profound than for their fungal orthologs, with some notable exceptions. Pictures emerge, however, for both groups, highlighting two important aspects: (i) Photoreceptors are placed high on the regulatory pyramid, and (ii) photoreceptors are part of a maze of interacting proteins, be they other photoreceptors or, e.g., hormone receptors, in some cases in a concurrent activity, in other cases counteracting with each other. Several interesting aspects seem to emerge for plant-pathogenic bacteria such that the photoreceptors keep the game under control. In other words, these light-sensitive proteins seem to control infectivity and virulence to a level that generates not too much harm to the plant host. This becomes particularly evident when the photoreceptor genes are interrupted causing remarkably increased infectivity and in-leaf distribution of the bacteria, eventually causing tissue collapse and plant death. Nearly no information could be compiled on the downstream processes like signalling cascades or the 
molecular mechanisms of gene expression control that eventually result in a bacterial or fungal attack against a plant host [7].

The more complex lifestyle of fungi allows expecting even more sophisticated interactions with plants. From the data collected in this work no general picture emerges that can answer the question: do fungal photoreceptors affect fungi-plant interaction, in particular pathogenicity towards plants? It is clear that light and photoreceptors affect fungal reproductive traits, but only in few cases a correlation with specific features connected to virulence and or infectivity could be established, mentioning only the production of mycotoxins, hormones and other metabolites (see Table 4). It is also emerging that photoreceptors have an impact, mostly positive, on the resistance to stressors (e.g., UV radiation, ROS, osmotic stress) also by promoting the production of protective pigments and PHR proteins; these aspects certainly deserve more attention, in that they may have an impact on fungal survival rate under severe conditions. This is also true for non-phyto-pathogenic fungi used for the biocontrol of insect pests (see Table 5) for which again it is difficult, with the few data available, to answer the question: do photoreceptors influence the pathogenicity towards insects? To our knowledge, the answer is at hand only for the case of Beauveria bassiana, for which the $\mathrm{BL}$ receptors VVD was found to control virulence towards insects [178].

One aspect that came to light-still for only few reported cases-is the finding that the presence of photoreceptor genes is instrumental for the invading activity of bacteria and of fungi also in the dark. These observations point to the need of an intact region in their genome not allowing an interruption of transcriptional read-through. In these reported cases, the photoreceptor genes are located within (or are part of) a virulence 'island' or a plasmid carrying virulence-activating genes. Whether light activation adds to this 'dark activity', remains still an open question.

Light sensing in the plant microbiota has many more unexplored aspects; we cite here Methylobacteria, ubiquitous inhabitants of the phyllosphere belonging to pinkpigmented facultative methylotrophic (PPFMs) alpha-proteobacteria that exploit $\mathrm{C} 1$ compounds synthesised by the host plant, in turn producing phytohormones that promote plant growth [188]. Methylobacteria possess genes for an impressive number of photoreceptors, chiefly belonging to LOV and BphP proteins, whose preliminary investigation demonstrated the expected light-triggered reactions [18]. The functional role of Methylobacteria photoreceptors is fully unknown but, given the high potential of these organisms as plant probiotics and for biotechnological applications [21, 188], the relevance of their photosensors in vivo should be definitely investigated. Last but not least we note that photoreceptor proteins of microbes living under variable environmental conditions, might show peculiar properties suitable for applications [31, 189]. As an example and again referring to Methylobacteria, a LOV protein from M. radiotolerans has turned out to be an efficient photosensitiser for singlet oxygen formation after insertion of a single mutation, concomitanly showing an astonishing resistance to denaturation with urea [190].

Supplementary Information The online version contains supplementary material available at https://doi.org/10.1007/s43630-021-00029-7.

Author contributions The authors contributed equally to this work.

Funding Open access funding provided by Università degli Studi di Parma within the CRUI-CARE Agreement. No support.

\section{Compliance with ethical standard}

Conflicts of interest The authors declare that they have no conflict of interests.

Availability of data and material All materials can be made available.

Open Access This article is licensed under a Creative Commons Attribution 4.0 International License, which permits use, sharing, adaptation, distribution and reproduction in any medium or format, as long as you give appropriate credit to the original author(s) and the source, provide a link to the Creative Commons licence, and indicate if changes were made. The images or other third party material in this article are included in the article's Creative Commons licence, unless indicated otherwise in a credit line to the material. If material is not included in the article's Creative Commons licence and your intended use is not permitted by statutory regulation or exceeds the permitted use, you will need to obtain permission directly from the copyright holder. To view a copy of this licence, visit http://creativecommons.org/licenses/by/4.0/.

\section{References}

1. Müller, D. B., Vogel, C., Bai, Y., \& Vorholt, J. A. (2016). The plant microbiota: systems-level insights and perspectives. Annual Review of Genetics, 50(1), 211-234.

2. Cheng, Y. T., Zhang, L., \& He, S. Y. (2019). Plant-microbe interactions facing environmental challenge. Cell Host and Microbe, 26(2), 183-192.

3. Vannier, N., Agler, M., \& Hacquard, S. (2019). Microbiotamediated disease resistance in plants. PLOS Pathogens, 15(6), e1007740.

4. Schirawski, J., \& Perlin, M. H. (2018). Plant-microbe interaction 2017 - the good, the bad and the diverse. International Journal of Molecular Sciences, 19(5), 1374.

5. Beattie, G. A., Hatfield, B. M., Dong, H., \& McGrane, R. S. (2018). Seeing the light: the roles of red- and blue-light sensing in plant microbes. Annual Review of Phytopathology, 56, 41-66.

6. Alsanius, B. W., Karlsson, M., Rosberg, A. K., Dorais, M., Naznin, M. T., Khalil, S., et al. (2019). Light and microbial lifestyle: the impact of light quality on plant-microbe interactions in horticultural production systems-a review. Horticulturae, 5(2), 41. 
7. Kraiselburd, I., Moyano, L., Carrau, A., Tano, J., \& Orellano, E. G. (2017). Bacterial photosensory proteins and their role in plant-pathogen interactions. Photochemistry and Photobiology, 93(3), 666-674.

8. Moyano, L., Carrau, A., Petrocelli, S., Kraiselburd, I., Gärtner, W., \& Orellano, E. G. (2020). Bacteriophytochromes from Pseudomonas syringae pv. tomato DC3000 modulate the early stages of plant colonization during bacterial speck disease. European Journal of Plant Pathology, 156(3), 695-712.

9. Herrera-Estrella, A., \& Horwitz, B. A. (2007). Looking through the eyes of fungi: molecular genetics of photoreception. Molecular Microbiology, 64(1), 5-15.

10. Mandalari, C., Losi, A., \& Gärtner, W. (2013). Distance-tree analysis, distribution and co-presence of bilin- and flavin-binding prokaryotic photoreceptors for visible light. Photochemical and Photobiological Sciences, 12(7), 1144-1157.

11. Kavakli, I. H., Baris, I., Tardu, M., Gül, Ş, Öner, H., Çal, S., et al. (2017). The Photolyase/cryptochrome family of proteins as DNA repair enzymes and transcriptional repressors. Photochemistry and Photobiology, 93(1), 93-103.

12. Park, S.-Y., \& Tame, J. R. H. (2017). Seeing the light with BLUF proteins. Biophysical Reviews, 9(2), 169-176.

13. Kaushik, M., Sharma, R., Veetil, S., Srivastava, S., \& Kateriya, S. (2019). Modular diversity of the BLUF proteins and their potential for the development of diverse optogenetic tools. Applied Sciences, 9(18), 3924.

14. Ernst, O. P., Lodowski, D. T., Elstner, M., Hegemann, P., Brown, L. S., \& Kandori, H. (2014). Microbial and animal rhodopsins: structures, functions, and molecular mechanisms. Chemical Reviews, 114(1), 126-163.

15. Cao, Z., Buttani, V., Losi, A., \& Gärtner, W. (2008). A blue light inducible two-component signal transduction system in the plant pathogen Pseudomonas syringae pv. tomato. Biophysical Journal, 94(3), 897-905.

16. Shah, R., Schwach, J., Frankenberg-Dinkel, N., \& Gärtner, W. (2012). Complex formation between heme oxygenase and phytochrome during biosynthesis in Pseudomonas syringae pv. tomato. Photochemical and Photobiological Sciences, 11(6), 1026-1031.

17. Consiglieri, E., Gutt, A., Gärtner, W., Schubert, L., Viappiani, C., Abbruzzetti, S., et al. (2019). Dynamics and efficiency of photoswitching in biliverdin-binding phytochromes. Photochemical and Photobiological Sciences, 18(10), 2484-2496.

18. Consiglieri, E., Xu, Q., Zhao, K.-H., Gärtner, W., \& Losi, A. (2020). First molecular characterisation of blue- and red-light photoreceptors from Methylobacterium radiotolerans. Physical Chemistry Chemical Physics, 22(22), 12434-12446.

19. Green, P. N., \& Ardley, J. K. (2018). Review of the genus Methylobacterium and closely related organisms: a proposal that some Methylobacterium species be reclassified into a new genus, Methylorubrum gen. nov. International Journal of Systematic and Evolutionary Microbiology, 68(9), 2727-2748.

20. Kumar, M., Kour, D., Yadav, A. N., Saxena, R., Rai, P. K., Jyoti, A., et al. (2019). Biodiversity of methylotrophic microbial communities and their potential role in mitigation of abiotic stresses in plants. Biologia, 74(3), 287-308.

21. Kumar, M., Tomar, R. S., Lade, H., \& Paul, D. (2016). Methylotrophic bacteria in sustainable agriculture. World journal of microbiology \& biotechnology, 32(7), 120.

22. Schumacher, J., \& Gorbushina, A. A. (2020). Light sensing in plant- and rock-associated black fungi. Fungal Biology, 124(5), 407-417.

23. Corrochano, L. M. (2019). Light in the fungal world: from photoreception to gene transcription and beyond. Annual Review of Genetics, 53(1), 149-170.
24. Guzmán-Guzmán, P., Porras-Troncoso, M. D., Olmedo-Monfil, V., \& Herrera-Estrella, A. (2019). Trichoderma species: versatile plant symbionts. Phytopathology, 109(1), 6-16.

25. Carvalho, S. D., \& Castillo, J. A. (2018). Influence of light on plant-phyllosphere interaction. Frontiers in Plant Science, 9, 1482.

26. Cohen, Y., Vaknin, M., Ben-Naim, Y., \& Rubin, A. E. (2013). Light suppresses sporulation and epidemics of Peronospora belbahrii. PLoS ONE, 8(11), e81282.

27. Choudhury, R. A., \& McRoberts, N. (2018). Temperature and light effects on in vitro germination of Peronospora effusa sporangia. Tropical Plant Pathology, 43(6), 572-576.

28. Anders, K., \& Essen, L.-O. (2015). The family of phytochromelike photoreceptors: diverse, complex and multi-colored, but very useful. Current Opinion in Structural Biology, 35, 7-16.

29. Fushimi, K., \& Narikawa, R. (2019). Cyanobacteriochromes: photoreceptors covering the entire UV-to-visible spectrum. Current Opinion in Structural Biology, 57, 39-46.

30. Mitchell, A. L., Attwood, T. K., Babbitt, P. C., Blum, M., Bork, P., Bridge, A., et al. (2019). InterPro in 2019: improving coverage, classification and access to protein sequence annotations. Nucleic Acids Research, 47(D1), D351-D360.

31. Gourinchas, G., Etzl, S., \& Winkler, A. (2019). Bacteriophytochromes-from informative model systems of phytochrome function to powerful tools in cell biology. Current Opinion in Structural Biology, 57, 72-83.

32. Buhrke, D., Kuhlmann, U., Michael, N., \& Hildebrandt, P. (2018). The photoconversion of phytochrome includes an unproductive shunt reaction pathway. ChemPhysChem, 19(5), $566-570$

33. Khorchid, A., \& Ikura, M. (2006). Bacterial histidine kinase as signal sensor and transducer. International Journal of Biochemistry and Cell Biology, 38(3), 307-312.

34. Möglich, A. (2019). Signal transduction in photoreceptor histidine kinases. Protein Science, 28(11), 1923-1946.

35. Chernov, K. G., Redchuk, T. A., Omelina, E. S., \& Verkhusha, V. V. (2017). Near-infrared fluorescent proteins, biosensors, and optogenetic tools engineered from phytochromes. Chemical Reviews, 117(9), 6423-6446.

36. Losi, A., \& Gärtner, W. (2017). Solving blue light riddles: new lessons from flavin-binding LOV photoreceptors. Photochemistry and Photobiology, 93(1), 141-158.

37. Glantz, S. T., Carpenter, E. J., Melkonian, M., Gardner, K. H., Boyden, E. S., Wong, G.K.-S., et al. (2016). Functional and topological diversity of LOV domain photoreceptors. Proceedings of the National Academy of Sciences of the United States of America, 113(11), E1442-1451.

38. Losi, A., Mandalari, C., \& Gärtner, W. (2015). The evolution and functional role of flavin-based prokaryotic photoreceptors. Photochemistry and Photobiology, 91(5), 1021-1031.

39. Ozturk, N. (2017). Phylogenetic and functional classification of the photolyase/cryptochrome family. Photochemistry and Photobiology, 93(1), 104-111.

40. Franz-Badur, S., Penner, A., Straß, S., von Horsten, S., Linne, U., \& Essen, L. O. (2019). Structural changes within the bifunctional cryptochrome/photolyase CraCRY upon blue light excitation. Scientific Reports, 9(1), 1-8.

41. Chaves, I., Pokorny, R., Byrdin, M., Hoang, N., Ritz, T., Brettel, K., et al. (2011). The cryptochromes: blue light photoreceptors in plants and animals. Annual Review of Plant Biology, $62,335-364$.

42. Zhang, M., Wang, L., \& Zhong, D. (2017). Photolyase: dynamics and electron-transfer mechanisms of DNA repair. Archives of Biochemistry and Biophysics, 632, 158-174.

43. Kottke, T., Oldemeyer, S., Wenzel, S., Zou, Y., \& Mittag, M. (2017). Cryptochrome photoreceptors in green algae: 
unexpected versatility of mechanisms and functions. Journal of Plant Physiology, 217, 4-14.

44. Kottke, T., Xie, A., Larsen, D. S., \& Hoff, W. D. (2018). Photoreceptors take charge: emerging principles for light sensing. Annual Review of Biophysics, 47, 291-313.

45. Kandori, H. (2020). Biophysics of rhodopsins and optogenetics. Biophysical Reviews, 12(2), 355-361.

46. Mukherjee, S., Hegemann, P., \& Broser, M. (2019). Enzymerhodopsins: novel photoregulated catalysts for optogenetics. Current Opinion in Structural Biology, 57, 118-126.

47. An, S.-Q., Potnis, N., Dow, M., Vorhölter, F.-J., He, Y.-Q., Becker, A., et al. (2020). Mechanistic insights into host adaptation, virulence and epidemiology of the phytopathogen Xanthomonas. FEMS microbiology reviews, 44(1), 1-32.

48. Kraiselburd, I., Gutt, A., Losi, A., Gärtner, W., \& Orellano, E. G. (2015). Functional characterization of a LOV-histidine kinase photoreceptor from Xanthomonas citri subsp. citri. Photochemistry and Photobiology, 91(5), 1123-1132.

49. Kraiselburd, I., Daurelio, L. D., Tondo, M. L., Merelo, P., Cortadi, A. A., Talón, M., et al. (2013). The LOV protein of Xanthomonas citri subsp. citri plays a significant role in the counteraction of plant immune responses during citrus canker. PLoS ONE, 8(11), e80930.

50. Bonomi, H. R., Toum, L., Sycz, G., Sieira, R., Toscani, A. M., Gudesblat, G. E., et al. (2016). Xanthomonas campestris attenuates virulence by sensing light through a bacteriophytochrome photoreceptor. EMBO Reports, 17(11), 1565-1577.

51. Xin, X.-F., \& He, S. Y. (2013). Pseudomonas syringae pv. tomato DC3000: a model pathogen for probing disease susceptibility and hormone signaling in plants. Annual Review of Phytopathology, 51(1), 473-498.

52. Wilson, M., Campbell, H. L., Ji, P., Jones, J. B., \& Cuppels, D. A. (2002). Biological control of bacterial speck of tomato under field conditions at several locations in North America. Phytopathology, 92(12), 1284-1292.

53. Ricci, A., Dramis, L., Shah, R., Gärtner, W., \& Losi, A. (2015). Visualizing the relevance of bacterial blue- and red-light receptors during plant-pathogen interaction. Environmental Microbiology Reports, 7, 795-802.

54. Shah, R., Pathak, G., Drepper, T., \& Gärtner, W. (2016). Selective photoreceptor gene knock-out reveals a regulatory role for the growth behavior of Pseudomonas syringae. Photochemistry and Photobiology, 92(4), 571-578.

55. Moriconi, V., Sellaro, R., Ayub, N., Soto, G., Rugnone, M., Shah, R., et al. (2013). LOV-domain photoreceptor, encoded in a genomic island, attenuates the virulence of Pseudomonas syringae in light-exposed Arabidopsis leaves. Plant Journal, 76(2), 322-331.

56. Santamaría-Hernando, S., Rodríguez-Herva, J. J., MartínezGarcía, P. M., Río-Álvarez, I., González-Melendi, P., Zamorano, J., et al. (2018). Pseudomonas syringae pv. tomato exploits light signals to optimize virulence and colonization of leaves. Environmental Microbiology, 20(12), 4261-4280.

57. Oberpichler, I., Rosen, R., Rasouly, A., Vugman, M., Ron, E. Z., \& Lamparter, T. (2008). Light affects motility and infectivity of Agrobacterium tumefaciens. Environmental Microbiology, 10(8), 2020-2029.

58. Yang, Y. X., Wang, M. M., Yin, Y. L., Onac, E., Zhou, G. F., Peng, S., et al. (2015). RNA-seq analysis reveals the role of red light in resistance against Pseudomonas syringae pv. tomato DC3000 in tomato plants. BMC Genomics, 16(1), 120.

59. Moyano, L., Lopéz-Fernández, M. P., Carrau, A., Nannini, J. M., Petrocelli, S., Orellano, E. G., et al. (2020). Red light delays programmed cell death in non-host interaction between $\mathrm{Pseu}$ domonas syringae pv. tomato DC3000 and tobacco plants. Plant Science, 291, 110361.
60. Feil, H., Feil, W. S., Chain, P., Larimer, F., DiBartolo, G., Copeland, A., et al. (2005). Comparison of the complete genome sequences of Pseudomonas syringae pv. syringae B728a and pv tomato DC3000. Proceedings of the National Academy of Sciences of the United States of America, 102(31), 11064-11069.

61. McGrane, R., \& Beattie, G. A. (2017). Pseudomonas syringae pv. syringae $\mathrm{B} 728$ a regulates multiple stages of plant colonization via the bacteriophytochrome BphP1. MBio, 8, e01178.

62. Wu, L., McGrane, R. S., \& Beattie, G. A. (2013). Light regulation of swarming motility in Pseudomonas syringae integrates signaling pathways mediated by a bacteriophytochrome and a LOV protein. mBio, 4,334 .

63. Cheng, D.-D., Liu, M.-J., Sun, X.-B., Zhao, M., Chow, W. S., Sun, G.-Y., et al. (2016). Light suppresses bacterial population through the accumulation of hydrogen peroxide in tobacco leaves infected with Pseudomonas syringae pv. Tabaci. Frontiers in Plant Science, 7(APR2016), 512.

64. Rajalingam, N., \& Lee, Y. H. (2018). Effects of green light on the gene expression and virulence of the plant pathogen Pseudomonas cichorii JBC1. European Journal of Plant Pathology, 150(1), 223-236.

65. Walker, T. S., Bais, H. P., Déziel, E., Schweizer, H. P., Rahme, L. G., Fall, R., et al. (2004). Pseudomonas aeruginosa-plant root interactions pathogenicity, biofilm formation, and root exudation. Plant Physiology, 134(1), 320-331.

66. Mukherjee, S., Jemielita, M., Stergioula, V., Tikhonov, M., \& Bassler, B. L. (2019). Photosensing and quorum sensing are integrated to control Pseudomonas aeruginosa collective behaviors. PLoS Biology, 17(12), e3000579.

67. Kahl, L. J., Price-Whelan, A., \& Dietrich, L. E. P. (2020). Lightmediated decreases in cyclic di-GMP levels inhibit structure formation in Pseudomonas aeruginosa biofilms. Journal of Bacteriology, 202(14), e00117-e120.

68. Simm, R., Morr, M., Kader, A., Nimtz, M., \& Römling, U. (2004). GGDEF and EAL domains inversely regulate cyclic diGMP levels and transition from sessibility to motility. Molecular Microbiology, 53(4), 1123-1134.

69. Yee, E. F., Diensthuber, R. P., Vaidya, A. T., Borbat, P. P., Engelhard, C., Freed, J. H., et al. (2015). Signal transduction in lightoxygen-voltage receptors lacking the adduct-forming cysteine residue. Nature Communications, 6(1), 1-10.

70. Kopka, B., Magerl, K., Savitsky, A., Davari, M. D., Röllen, K., Bocola, M., et al. (2017). Electron transfer pathways in a light, oxygen, voltage (LOV) protein devoid of the photoactive cysteine. Scientific Reports, 7(1), 13346.

71. Verma, R. K., Biswas, A., Kakkar, A., Pradhan, B. B., \& Chatterjee, S. (2020). A Bacteriophytochrome mediates interplay between light sensing and the second messenger cyclic Di-GMP to control bacterial social behaviors. SSRN Electronic Journal, 32(13), 108202.

72. Meyer, T., Renoud, S., Vigouroux, A., Miomandre, A., Gaillard, V., Kerzaon, I., et al. (2018). Regulation of hydroxycinnamic acid degradation drives Agrobacterium fabrum lifestyles. Molecular Plant-Microbe Interactions, 31(8), 814-822.

73. Nester, E. W. (2015). Agrobacterium: nature's genetic engineer. Frontiers in Plant Science, 5, 730.

74. Lamparter, T., Krauß, N., \& Scheerer, P. (2017). Phytochromes from Agrobacterium fabrum. Photochemistry and Photobiology, 93, 642-655.

75. Schmidt, A., Sauthof, L., Szczepek, M., Lopez, M. F., Escobar, F. V., Qureshi, B. M., et al. (2018). Structural snapshot of a bacterial phytochrome in its functional intermediate state. Nature Communications, 9(1), 4912.

76. Xue, P., El Kurdi, A., Kohler, A., Ma, H., Kaeser, G., Ali, A., et al. (2019). Evidence for weak interaction between 
phytochromes Agp1 and Agp2 from Agrobacterium fabrum. FEBS Letters, 593(9), 926-941.

77. Lamparter, T., Michael, N., Mittmann, F., \& Esteban, B. (2002). Phytochrome from Agrobacterium tumefaciens has unusual spectral properties and reveals an $\mathrm{N}$-terminal chromophore attachment site. Proceedings of the National Academy of Sciences, 99(18), 11628-11633.

78. Bai, Y., Rottwinkel, G., Feng, J., Liu, Y., \& Lamparter, T. (2016). Bacteriophytochromes control conjugation in Agrobacterium fabrum. Journal of Photochemistry and Photobiology B Biology, 161, 192-199.

79. Xue, P., Bai, Y., Rottwinkel, G., Averbukh, E., Ma, Y., Roeder, T., et al. (2020). Phytochrome mediated responses in Agrobacterium fabrum: growth, swimming, plant infection and interbacterial competition. bioRxiv. https://doi.org/10.1101/2020.04.24.060905

80. Kumar, S., Kateriya, S., Singh, V. S., Tanwar, M., Agarwal, S., Singh, H., et al. (2012). Bacteriophytochrome controls carotenoid-independent response to photodynamic stress in a nonphotosynthetic rhizobacterium, Azospirillum brasilense Sp7. Scientific Reports, 2, 872.

81. Romina, M., Gastón, L., Belén, R., Susana, R., Verónica, M., \& Fabricio, C. (2020). Evaluation of growth and motility in nonphotosynthetic Azospirillum brasilense exposed to red, blue, and white light. Archives of Microbiology, 202(5), 1193-1201.

82. Bonomi, H. R., Posadas, D. M., Paris, G., Del Carmen Carrica, M., Frederickson, M., Pietrasanta, L. I., et al. (2012). Light regulates attachment, exopolysaccharide production, and nodulation in Rhizobium leguminosarum through a LOV-histidine kinase photoreceptor. Proceedings of the National Academy of Sciences of the United States of America, 109(30), 12135-12140.

83. Giraud, E., \& Fleischman, D. (2004). Nitrogen-fixing symbiosis between photosynthetic bacteria and legumes. Photosynthesis Research, 82(2), 115-130.

84. Avontuur, J. R., Palmer, M., Beukes, C. W., Chan, W. Y., Coetzee, M. P. A., Blom, J., et al. (2019). Genome-informed Bradyrhizobium taxonomy: where to from here? Systematic and Applied Microbiology, 42(4), 427-439.

85. Alves, B. J. R., Boddey, R. M., \& Urquiaga, S. (2003). The success of BNF in soybean in Brazil. Plant and Soil, 252(1), 1-9.

86. Wang, J. Y., Wang, R., Zhang, Y. M., Liu, H. C., Chen, W. F., Wang, E. T., et al. (2013). Bradyrhizobium daqingense sp. nov., isolated from soybean nodules. International Journal of Systematic and Evolutionary Microbiology, 63, 616-624.

87. Stępkowski, T., Banasiewicz, J., Granada, C., Andrews, M., \& Passaglia, L. (2018). Phylogeny and phylogeography of rhizobial symbionts nodulating legumes of the tribe genisteae. Genes, 9(3), 163.

88. Rottwinkel, G., Oberpichler, I., \& Lamparter, T. (2010). Bathy phytochromes in rhizobial soil bacteria. Journal of Bacteriology, 192(19), 5124-5133.

89. Giraud, E., Fardoux, J., Fourrier, N., Hannibal, L., Genty, B., Bouyer, P., et al. (2002). Bacteriophytochrome controls photosystem synthesis in anoxygenic bacteria. Nature, 417(6885), 202-205.

90. Jaubert, M., Lavergne, J., Fardoux, J., Hannibal, L., Vuillet, L., Adriano, J. M., et al. (2007). A singular bacteriophytochrome acquired by lateral gene transfer. Journal of Biological Chemistry, 282(10), 7320-7328.

91. Jaubert, M., Vuillet, L., Hannibal, L., Adriano, J. M., Fardoux, J., Bouyer, P., et al. (2008). Control of peripheral light-harvesting complex synthesis by a bacteriophytochrome in the aerobic photosynthetic bacterium Bradyrhizobium strain BTAi1. Journal of Bacteriology, 190(17), 5824-5831.

92. Chowdhury, S. P., Hartmann, A., Gao, X. W., \& Borriss, R. (2015). Biocontrol mechanism by root-associated Bacillus amyloliquefaciens FZB42-a review. Frontiers in Microbiology, 6, 780 .

93. Ramkumar, G., Yu, S. M., \& Lee, Y. H. (2013). Influence of light qualities on antifungal lipopeptide synthesis in Bacillus amyloliquefaciens JBC36. European Journal of Plant Pathology, 137(2), 243-248.

94. Yu, S. M., \& Lee, Y. H. (2013). Effect of light quality on Bacillus amyloliquefaciens JBC36 and its biocontrol efficacy. Biological Control, 64(3), 203-210.

95. Losi, A., Polverini, E., Quest, B., \& Gärtner, W. (2002). First evidence for phototropin-related blue-light receptors in prokaryotes. Biophysical Journal, 82, 2627-2634.

96. Nicholson, W. L. (1995). Photoreactivation in the genus Bacillus. Current Microbiology, 31(6), 361-364.

97. Melo, A. L. D. A., Soccol, V. T., \& Soccol, C. R. (2016). Bacillus thuringiensis: mechanism of action, resistance, and new applications: a review. Critical Reviews in Biotechnology, 36(2), 317-326.

98. Williamson, B., Tudzynski, B., Tudzynski, P., \& Van Kan, J. A. L. (2007). Botrytis cinerea: the cause of grey mould disease. Molecular Plant Pathology, 8(5), 561-580.

99. Park, H. S., \& Yu, J. H. (2012). Genetic control of asexual sporulation in filamentous fungi. Current Opinion in Microbiology, 15(6), 669-677.

100. Schumacher, J. (2017). How light affects the life of Botrytis Fungal Genetics and Biology, 106, 26-41.

101. Jarvis, W. R. (1972). Phototropism in Botrytis cinerea. Transactions of the British Mycological Society, 58(3), 526.

102. Upadhyay, A., Brunner, M., \& Herzel, H. (2019). An inactivation switch enables rhythms in a Neurospora clock model. International Journal of Molecular Sciences, 20(12), 2985.

103. Corrochano, L. M. (2007). Fungal photoreceptors: sensory molecules for fungal development and behaviour. Photochemical and Photobiological Sciences, 6(7), 725-736.

104. Gin, E., Diernfellner, A. C. R., Brunner, M., \& Höfer, T. (2013). The Neurospora photoreceptor VIVID exerts negative and positive control on light sensing to achieve adaptation. Molecular Systems Biology, 9(1), 667.

105. Dasgupta, A., Fuller, K. K., Dunlap, J. C., \& Loros, J. J. (2016). Seeing the world differently: variability in the photosensory mechanisms of two model fungi. Environmental Microbiology, 18(1), 5-20.

106. Chen, C. H., DeMay, B. S., Gladfelter, A. S., Dunlap, J. C., \& Loros, J. J. (2010). Physical interaction between vivid and white collar complex regulates photoadaptation in Neurospora. Proceedings of the National Academy of Sciences of the United States of America, 107(38), 16715-16720.

107. Yu, Z., \& Fischer, R. (2019). Light sensing and responses in fungi. Nature Reviews Microbiology, 17(1), 25-36.

108. Druzhinina, I. S., \& Kubicek, C. P. (2017). Genetic engineering of Trichoderma reesei cellulases and their production. Microbial Biotechnology, 10(6), 1485-1499.

109. Schmoll, M., Esquivel-Naranjo, E. U., \& Herrera-Estrella, A. (2010). Trichoderma in the light of day-physiology and development. Fungal Genetics and Biology, 47(11), 909-916.

110. Lokhandwala, J., Hopkins, H. C., Rodriguez-Iglesias, A., Dattenböck, C., Schmoll, M., \& Zoltowski, B. D. (2015). Structural biochemistry of a fungal LOV domain photoreceptor reveals an evolutionarily conserved pathway integrating light and oxidative stress. Structure, 23(1), 116-125.

111. Schmoll, M. (2018). Light, stress, sex and carbon-the photoreceptor ENVOY as a central checkpoint in the physiology of Trichoderma reesei. Fungal Biology, 122(6), 479-486.

112. Wang, Z., Li, N., Li, J., Dunlap, J. C., Trail, F., \& Townsend, J. P. (2016). The fast-evolving phy-2 gene modulates sexual 
development in response to light in the model fungus Neurospora crassa. mBio, 7(2), e02148.

113. Wang, Z., Wang, J., Li, N., Li, J., Trail, F., Dunlap, J. C., et al. (2018). Light sensing by opsins and fungal ecology: NOP-1 modulates entry into sexual reproduction in response to environmental cues. Molecular Ecology, 27(1), 216-232.

114. Bayram, Ö., Braus, G. H., Fischer, R., \& Rodriguez-Romero, J. (2010). Spotlight on Aspergillus nidulans photosensory systems. Fungal Genetics and Biology, 47(11), 900-908.

115. Purschwitz, J., Müller, S., Kastner, C., Schöser, M., Haas, H., Espeso, E. A., et al. (2008). Functional and physical interaction of blue- and red-light sensors in Aspergillus nidulans. Current Biology, 18(4), 255-259.

116. Ruger-Herreros, C., Rodríguez-Romero, J., Fernández-Barranco, R., Olmedo, M., Fischer, R., Corrochano, L. M., et al. (2011). Regulation of conidiation by light in Aspergillus nidulans. Genetics, 188(4), 809-822.

117. Blumenstein, A., Vienken, K., Tasler, R., Purschwitz, J., Veith, D., Frankenberg-Dinkel, N., et al. (2005). The Aspergillus nidulans phytochrome FphA represses sexual development in red light. Current Biology, 15(20), 1833-1838.

118. Yu, Z., Ali, A., Igbalajobi, O. A., Streng, C., Leister, K., Krauß, N., et al. (2019). Two hybrid histidine kinases, TcsB and the phytochrome FphA, are involved in temperature sensing in Aspergillus nidulans. Molecular Microbiology, 112, 1814-1830.

119. Yu, Z., Armant, O., \& Fischer, R. (2016). Fungi use the SakA (HogA) pathway for phytochrome-dependent light signalling. Nature Microbiology, 1(5), 1-7.

120. Marcos, A. T., Ramos, M. S., Schinko, T., Strauss, J., \& Cánovas, D. (2020). Nitric oxide homeostasis is required for light-dependent regulation of conidiation in Aspergillus. Fungal Genetics and Biology, 137, 103337.

121. Yu, Z., Hübner, J., Herrero, S., Gourain, V., \& Fischer, R. (2020). On the role of the global regulator RlcA in red-light sensing in Aspergillus nidulans. Fungal Biology, 124(5), 447-457.

122. Hedtke, M., Rauscher, S., Röhrig, J., Rodríguez-Romero, J., Yu, Z., \& Fischer, R. (2015). Light-dependent gene activation in Aspergillus nidulans is strictly dependent on phytochrome and involves the interplay of phytochrome and white collar-regulated histone H3 acetylation. Molecular Microbiology, 97(4), 733-745.

123. Brandt, S., von Stetten, D., Günther, M., Hildebrandt, P., \& Frankenberg-Dinkel, N. (2008). The fungal phytochrome FphA from Aspergillus nidulans. The Journal of Biological Chemistry, 283(50), 34605-34614.

124. Fraeyman, S., Croubels, S., Devreese, M., \& Antonissen, G. (2017). Emerging fusarium and alternaria mycotoxins: occurrence, toxicity and toxicokinetics. Toxins, 9(7), 1-26.

125. de Pontes, J. G. M., Fernandes, L. S., Dos Santos, R., Vander, R., Tasic, L., \& Fill, T. P. (2020). Virulence factors in the phytopathogen-host interactions: an overview. Journal of Agricultural and Food Chemistry, 68(29), 7555-7570.

126. Igbalajobi, O., Yu, Z., \& Fischer, R. (2019). Red-and blue-light sensing in the plant pathogen Alternaria alternata depends on phytochrome and the white-collar protein LreA. mBio, 10(2), e00371-19.

127. Canessa, P., Schumacher, J., Hevia, M. A., Tudzynski, P., \& Larrondo, L. F. (2013). Assessing the effects of light on differentiation and virulence of the plant pathogen Botrytis cinerea: characterization of the white collar complex. PLoS ONE, 8(12), e84223.

128. Cohrs, K. C., \& Schumacher, J. (2017). The two cryptochrome/ photolyase family proteins fulfill distinct roles in DNA photorepair and regulation of conidiation in the gray mold fungus Botrytis cinerea. Applied and Environmental Microbiology, 83(17), e00812-e817.
129. Schumacher, J., Simon, A., Cohrs, K. C., Viaud, M., \& Tudzynski, P. (2014). The transcription factor BcLTF1 regulates virulence and light responses in the necrotrophic plant pathogen Botrytis cinerea. PLoS Genetics, 10(1), e1004040.

130. Hu, Y., He, J., Wang, Y., Zhu, P., Zhang, C., Lu, R., et al. (2014). Disruption of a phytochrome-like histidine kinase gene by homologous recombination leads to a significant reduction in vegetative growth, sclerotia production, and the pathogenicity of Botrytis cinerea. Physiological and Molecular Plant Pathology, 85, 25-33.

131. Ji, Y., Ouzounis, T., Courbier, S., Kaiser, E., Nguyen, P. T., Schouten, H. J., et al. (2019). Far-red radiation increases dry mass partitioning to fruits but reduces Botrytis cinerea resistance in tomato. Environmental and Experimental Botany, 168, 103889 .

132. Glantz, S. T., Berlew, E. E., Jaber, Z., Schuster, B. S., Gardner, K. H., \& Chow, B. Y. (2018). Directly light-regulated binding of RGS-LOV photoreceptors to anionic membrane phospholipids. Proceedings of the National Academy of Sciences of the United States of America, 115(33), E7720-E7727.

133. Berlew, E. E., Kuznetsov, I. A., Yamada, K., Bugaj, L. J., \& Chow, B. Y. (2020). Optogenetic Rac1 engineered from membrane lipid-binding RGS-LOV for inducible lamellipodia formation. Photochemical and Photobiological Sciences, 19(3), 353-361.

134. Aoki, T., O'Donnell, K., \& Geiser, D. M. (2014). Systematics of key phytopathogenic Fusarium species: Current status and future challenges. Journal of General Plant Pathology, 80(3), 189-201.

135. Goswami, R. S., \& Kistler, H. C. (2004). Heading for disaster: Fusarium graminearum on cereal crops. Molecular Plant Pathology, 5(6), 515-525.

136. Jang, J. Y., Baek, S. G., Choi, J. H., Kim, S., Kim, J., Kim, D. W., et al. (2019). Characterization of nivalenol-producing Fusarium asiaticum that causes cereal head blight in korea. Plant Pathology Journal, 35(6), 543-552.

137. Cen, Y. K., Lin, J. G., Wang, Y. L., Wang, J. Y., Liu, Z. Q., \& Zheng, Y. G. (2020). The Gibberellin Producer Fusarium fujikuroi: methods and technologies in the current toolkit. Frontiers in Bioengineering and Biotechnology, 8, 232.

138. de Lamo, F. J., \& Takken, F. L. W. (2020). Biocontrol by Fusarium oxysporum using endophyte-mediated resistance. Frontiers in Plant Science, 11, 37.

139. Lombard, L., Sandoval-Denis, M., Lamprecht, S. C., \& Crous, P. W. (2019). Epitypification of Fusarium oxysporum —clearing the taxonomic chaos. Persoonia Molecular Phylogeny and Evolution of Fungi, 43, 1-47.

140. Kim, H., Kim, H.-K., Lee, S., \& Yun, S.-H. (2015). The white collar complex is involved in sexual development of Fusarium graminearum. PLoS ONE, 10(3), e0120293.

141. Kim, H., Son, H., \& Lee, Y. W. (2014). Effects of light on secondary metabolism and fungal development of Fusarium graminearum. Journal of Applied Microbiology, 116(2), 380-389.

142. Tang, Y., Zhu, P., Lu, Z., Qu, Y., Huang, L., Zheng, N., et al. (2020). The photoreceptor components FaWC1 and FaWC2 of Fusarium asiaticum cooperatively regulate light responses but play independent roles in virulence expression. Microorganisms, $8(3), 365$.

143. Castrillo, M., \& Avalos, J. (2014). Light-mediated participation of the VIVID-like protein of Fusarium fujikuroi VvdA in pigmentation and development. Fungal Genetics and Biology, 71, 9-20.

144. Castrillo, M., \& Avalos, J. (2015). The flavoproteins CryD and VvdA cooperate with the white collar protein WcoA in the control of photocarotenogenesis in Fusarium fujikuroi. PLoS ONE, 10(3), e0119785. 
145. Castrillo, M., García-Martínez, J., \& Avalos, J. (2013). Lightdependent functions of the Fusarium fujikuroi CryD DASH cryptochrome in development and secondary metabolism. Applied and Environmental Microbiology, 79(8), 2777-2788.

146. García-Martínez, J., Brunk, M., Avalos, J., \& Terpitz, U. (2015). The CarO rhodopsin of the fungus Fusarium fujikuroi is a lightdriven proton pump that retards spore germination. Scientific Reports, 5(1), 1-11.

147. Adam, A., Deimel, S., Pardo-Medina, J., García-Martínez, J., Konte, T., Limón, M., et al. (2018). Protein activity of the Fusarium fujikuroi rhodopsins $\mathrm{CarO}$ and OpsA and their relation to fungus-plant interaction. International Journal of Molecular Sciences, 19(1), 215.

148. Ruiz-Roldán, M. C., Garre, V., Guarro, J., Mariné, M., \& Roncero, M. I. G. (2008). Role of the white collar 1 photoreceptor in carotenogenesis, UV resistance, hydrophobicity, and virulence of Fusarium oxysporum. Eukaryotic Cell, 7(7), 1227-1230.

149. Guo, H., Liu, A., Wang, Y., Wang, T., Zhang, W., Zhu, P., et al. (2020). Measuring light-induced fungal ethylene production enables non-destructive diagnosis of disease occurrence in harvested fruits. Food Chemistry, 310, 125827.

150. Daub, M. E., Herrero, S., \& Chung, K.-R. (2005). Photoactivated perylenequinone toxins in fungal pathogenesis of plants. FEMS Microbiology Letters, 252(2), 197-206.

151. Shim, W. B., \& Dunkle, L. D. (2002). Identification of genes expressed during cercosporin biosynthesis in Cercospora zeaemaydis. Physiological and Molecular Plant Pathology, 61(4), 237-248.

152. Kim, H., Ridenour, J. B., Dunkle, L. D., \& Bluhm, B. H. (2011). Regulation of stomatal tropism and infection by light in Cercospora zeae-maydis: evidence for coordinated host/ pathogen responses to photoperiod? PLoS Pathogens, 7(7), e1002113.

153. Peres, N. A., Timmer, L. W., Adaskaveg, J. E., \& Correll, J. C. (2005). Lifestyles of Colletotrichum acutatum. Plant Disease, 89(8), 784-796.

154. Yu, S.-M., Ramkumar, G., \& Lee, Y. H. (2013). Light quality influences the virulence and physiological responses of Colletotrichum acutatum causing anthracnose in pepper plants. Journal of Applied Microbiology, 115(2), 509-516.

155. Wilson, R. A., \& Talbot, N. J. (2009). Under pressure: investigating the biology of plant infection by Magnaporthe oryzae. Nature Reviews Microbiology, 7(3), 185-195.

156. Kim, S., Singh, P., Park, J., Park, S., Friedman, A., Zheng, T., et al. (2011). Genetic and molecular characterization of a blue light photoreceptor MGWC-1 in Magnaporthe oryzae. Fungal Genetics and Biology, 48(4), 400-407.

157. Bowen, J. K., Mesarich, C. H., Bus, V. G. M., Beresford, R. M., Plummer, K. M., \& Templeton, M. D. (2011). Venturia inaequalis: the causal agent of apple scab. Molecular Plant Pathology, 12(2), 105-122.

158. Ehlert, K., Piepenbring, M., \& Kollar, A. (2017). Ascospore release in apple scab underlies infrared sensation. Fungal Biology, 121(12), 1054-1062.

159. Francisco, C. S., Ma, X., Zwyssig, M. M., McDonald, B. A., \& Palma-Guerrero, J. (2019). Morphological changes in response to environmental stresses in the fungal plant pathogen Zymoseptoria tritici. Scientific Reports, 9(1), 1-18.

160. McCorison, C. B., \& Goodwin, S. B. (2020). The wheat pathogen Zymoseptoria tritici senses and responds to different wavelengths of light. BMC Genomics, 21(1), 513.

161. Matei, A., \& Doehlemann, G. (2016). Cell biology of corn smut disease-Ustilago maydis as a model for biotrophic interactions. Current Opinion in Microbiology, 34, 60-66.

162. Brych, A., Mascarenhas, J., Jaeger, E., Charkiewicz, E., Pokorny, R., Bölker, M., et al. (2016). White collar 1-induced photolyase expression contributes to UV-tolerance of Ustilago maydis. MicrobiologyOpen, 5(2), 224-243.

163. Sánchez-Arreguin, J. A., Cabrera-Ponce, J. L., León-Ramírez, C. G., Camargo-Escalante, M. O., \& Ruiz-Herrera, J. (2020). Analysis of the photoreceptors involved in the light-depending basidiocarp formation in Ustilago maydis. Archives of Microbiology, 202(1), 93-103.

164. Panzer, S., Brych, A., Batschauer, A., \& Terpitz, U. (2019). Opsin 1 and Opsin 2 of the Corn Smut fungus Ustilago maydis are green light-driven proton pumps. Frontiers in Microbiology, 10,735 .

165. Ghosh, A. (2014). Small heat shock proteins (HSP12, HSP20 and HSP30) play a role in Ustilago maydis pathogenesis. FEMS Microbiology Letters, 361(1), 17-24.

166. Zeppa, S., Sisti, D., Pierleoni, R., Potenza, L., Guescini, M., Vallorani, L., et al. (2005). Tilia platyphyllos Scop.-Tuber brumale Vittad vs T platyphyllos Scop T borchii Vittad ectomycorrhizal systems: A comparison of structural and functional traits. Plant Physiology and Biochemistry, 43(7), 709-716.

167. Schneider-Maunoury, L., Deveau, A., Moreno, M., Todesco, F., Belmondo, S., Murat, C., et al. (2020). Two ectomycorrhizal truffles, Tuber melanosporum and T. aestivum, endophytically colonise roots of non-ectomycorrhizal plants in natural environments. New Phytologist, 225(6), 2542-2556.

168. Ambra, R., Grimaldi, B., Zamboni, S., Filetici, P., Macino, G., \& Ballario, P. (2004). Photomorphogenesis in the hypogeous fungus Tuber borchii: isolation and characterization of Tbwc-1, the homologue of the blue-light photoreceptor of Neurospora crassa. Fungal Genetics and Biology, 41(7), 688-697.

169. Gerace, R., Montanini, B., Proietto, M., Levati, E., De Luca, C., Brenna, A., et al. (2017). Photoreceptors in the dark: a functional white collar-like complex and other putative light-sensing components encoded by the genome of the subterranean fungus Tuber melanosporum. Fungal Biology, 121(3), 253-263.

170. Newcombe, G., Campbell, J., Griffith, D., Baynes, M., Launchbaugh, K., \& Pendleton, R. (2016). Revisiting the life cycle of dung fungi including Sordaria fimicola. PLOS ONE, 11(2), $\mathrm{e} 0147425$.

171. Krobanan, K., Liang, S. W., Chiu, H. C., \& Shen, W. C. (2019). The blue-light photoreceptor SfWC-1 gene regulates the phototropic response and fruiting-body development in the homothallic ascomycete Sordaria fimicola. Applied and Environmental Microbiology, 85(12), e02206-e2218.

172. Shah, P. A., \& Pell, J. K. (2003). Entomopathogenic fungi as biological control agents. Applied Microbiology and Biotechnology, 61(5-6), 413-423.

173. Tall, S., \& Meyling, N. V. (2018). Probiotics for plants? growth promotion by the entomopathogenic fungus Beauveria bassiana depends on nutrient availability. Microbial Ecology, 76(4), 1002-1008.

174. Dias, L. P., Pedrini, N., Braga, G. U. L., Ferreira, P. C., Pupin, B., Araújo, C. A. S., et al. (2019). Outcome of blue, green, red, and white light on Metarhizium robertsii during mycelial growth on conidial stress tolerance and gene expression. Fungal Biology, 124(5), 263-272.

175. Sasan, R. K., \& Bidochka, M. J. (2012). The insect-pathogenic fungus Metarhizium robertsii (Clavicipitaceae) is also an endophyte that stimulates plant root development. American Journal of Botany, 99(1), 101-107.

176. Brancini, G. T. P., Bachmann, L., da Ferreira, M. E., Rangel, D. E. N., \& Braga, G. U. L. (2018). Exposing Metarhizium acridum mycelium to visible light up-regulates a photolyase gene and increases photoreactivating ability. Journal of Invertebrate Pathology, 152, 35-37.

177. McKinnon, A. C., Glare, T. R., Ridgway, H. J., Mendoza-Mendoza, A., Holyoake, A., Godsoe, W. K., et al. (2018). Detection 
of the entomopathogenic fungus beauveria bassiana in the rhizosphere of wound-stressed Zea mays plants. Frontiers in Microbiology, 9, 1161.

178. Tong, S. M., Zhang, A. X., Guo, C. T., Ying, S. H., \& Feng, M. G. (2018). Daylight length-dependent translocation of VIVID photoreceptor in cells and its essential role in conidiation and virulence of Beauveria bassiana. Environmental Microbiology, 20(1), 169-185.

179. Qiu, L., Wang, J. J., Chu, Z. J., Ying, S. H., \& Feng, M. G. (2014). Phytochrome controls conidiation in response to red/ far-red light and daylight length and regulates multistress tolerance in Beauveria bassiana. Environmental Microbiology, 16(7), 2316-2328.

180. Quy, T., Andriana, Y., Khanh, T. D., \& Teschke, R. (2019). Cordycepin isolated from cordyceps militaris: its newly discovered herbicidal property and potential plant-based novel alternative to glyphosate. Molecules, 24(16), 2901.

181. Yang, T., Guo, M., Yang, H., Guo, S., \& Dong, C. (2016). The blue-light receptor CmWC-1 mediates fruit body development and secondary metabolism in Cordyceps militaris. Applied Microbiology and Biotechnology, 100(2), 743-755.

182. Zhang, J., Wang, F., Yang, Y., Wang, Y., \& Dong, C. (2020). CmVVD is involved in fruiting body development and carotenoid production and the transcriptional linkage among three blue-light receptors in edible fungus Cordyceps militaris. Environmental Microbiology, 22(1), 466-482.

183. Ikram, M., Ali, N., Jan, G., Iqbal, A., Hamayun, M., Jan, F. G., et al. (2019). Trichoderma reesei improved the nutrition status of wheat crop under salt stress. Journal of Plant Interactions, 14(1), 590-602.

184. Li, W. C., Huang, C. H., Chen, C. L., Chuang, Y. C., Tung, S. Y., \& Wang, T. F. (2017). Trichoderma reesei complete genome sequence, repeat-induced point mutation, and partitioning of CAZyme gene clusters. Biotechnology for Biofuels, 10(1), 170.
185. Casas-Flores, S., Rios-Momberg, M., Bibbins, M., Ponce-Noyola, P., \& Herrera-Estrella, A. (2004). BLR-1 and BLR-2, key regulatory elements of photoconidiation and mycelial growth in Trichoderma atroviride. Microbiology, 150(11), 3561-3569.

186. García-Esquivel, M., Esquivel-Naranjo, E. U., Hernández-Oñate, M. A., Ibarra-Laclette, E., \& Herrera-Estrella, A. (2016). The Trichoderma atroviride cryptochrome/photolyase genes regulate the expression of blr1-independent genes both in red and blue light. Fungal Biology, 120(4), 500-512.

187. Berrocal-Tito, G., Sametz-Baron, L., Eichenberg, K., Horwitz, B. A., \& Herrera-Estrella, A. (1999). Rapid blue light regulation of a Trichoderma harzianum photolyase gene. Journal of Biological Chemistry, 274(20), 14288-14294.

188. Dourado, M. N., Camargo Neves, A. A., Santos, D. S., \& Araújo, W. L. (2015). Biotechnological and agronomic potential of endophytic pink-pigmented methylotrophic Methylobacterium spp. BioMed Research International, 2015, 909016.

189. Losi, A., Gardner, K. H., \& Möglich, A. (2018). Blue-light receptors for optogenetics. Chemical Reviews, 118, 10659-10709.

190. Consiglieri, E., Xu, Q., Bregnhøj, M., Westberg, M., Ogilby, P. R., \& Losi, A. (2019). Single mutation in a novel bacterial LOV protein yields a singlet oxygen generator. Photochemical and Photobiological Sciences, 18(11), 2657-2660.

191. Río-Álvarez, I., Rodríguez-Herva, J. J., Martínez, P. M., González-Melendi, P., García-Casado, G., Rodríguez-Palenzuela, P., et al. (2014). Light regulates motility, attachment and virulence in the plant pathogen Pseudomonas syringae pv. tomato DC3000. Environmental Microbiology, 16, 2072-2085.

192. Kraiselburd, I., Alet, A. I., Tondo, M. L., Petrocelli, S., Daurelio, L. D., Monzón, J., et al. (2012). A LOV protein modulates the physiological attributes of Xanthomonas axonopodis pv. citri relevant for host plant colonization. PLOS ONE. https://doi. org/10.1371/journal.pone.0038226 